\title{
Toward an Enantioselective Total Synthesis of Sarain A: Construction of an Advanced Intermediate and Rearrangement of the Sarain A Core Under Mild Conditions.
}

Christopher J. Douglas, Sheldon Hiebert, and Larry E. Overman*

\section{Supporting Information}

\begin{abstract}
Contents
Part A. Experimental procedures for key transformations (preparation of 8, 11, 15, 16 and 17). Part B. Copies of ${ }^{1} \mathrm{H}$ and ${ }^{13} \mathrm{C}$ NMR spectra of new compounds, copies of COSY, HMQC, and HMBC spectra of $\mathbf{1 5}, \mathbf{1 6}$, and $\mathbf{1 7}$, and copy of the NOESY spectrum of $\mathbf{8}$.
\end{abstract}

Mannich Product 8. A 1 L round-bottom flask was charged with a magnetic stir bar, enol ethers 7 (7.79 g, $12.1 \mathrm{mmol}){ }^{1}$, and 2,6-di-tert-butyl-4-methyl pyridine (7.44 g, $\left.36.3 \mathrm{mmol}\right)$. The mixture was dried by azeotropic distillation with benzene $(3 \square 100 \mathrm{~mL})$. The flask was equipped with a sealable top and placed under an argon atmosphere. Methylene chloride (430 $\mathrm{mL}$ ) was added via syringe and the solution was cooled to $0{ }^{\circ} \mathrm{C}$. A solution of $\mathrm{BCl}_{3}(48.4 \mathrm{~mL}, 1.0$ $\mathrm{M}$ in heptane) was added in one portion via an oven-dried glass syringe and the solution was allowed to warm to rt. The vessel was sealed under an argon atmosphere. The colorless solution turned slightly pink and a cloudy precipitate slowly formed. The suspension was stirred gently for $15 \mathrm{~h}$ at $\mathrm{rt}$. The seal was opened to an $\mathrm{N}_{2}$ atmosphere and methylene chloride $(300 \mathrm{~mL})$ was added to the reaction mixture. The suspension was transferred by rapid cannulation into a solution of saturated aqueous $\mathrm{NaHCO}_{3}(350 \mathrm{~mL})$. The reaction vessel was washed with methylene chloride (3ち150 mL) and each wash was transferred to by cannulation to the quenching flask; all of the precipitate was transferred in the course of these four cannulations. The two homogeneous phases were separated and the aqueous portion was back-extracted with EtOAc $(5 \square 200 \mathrm{~mL})$. The combined organic extracts were washed with brine $(1 \square 200 \mathrm{~mL})$, dried $\left(\mathrm{MgSO}_{4}\right)$, and concentrated to give a slightly yellow foam which was analyzed by HPLC (Alltech Alltima 5 micron silica column $(250 \square 4.6 \mathrm{~mm}$ ), lot \# AT0153, with guard column, 1.0 $\mathrm{mL} / \mathrm{min} 75: 25$ EtOAc: $n$-hex, $\left.\square=254 \mathrm{~nm}, \mathrm{~T}_{\mathrm{R}}=11.79 \mathrm{~min}\right)$. Purification of this foam by flash chromatography (1:1 EtOAc:hex, then 2:1 EtOAc:hex, then 3:1 EtOAc:hex) gave 8 as a colorless

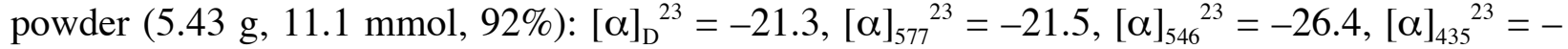

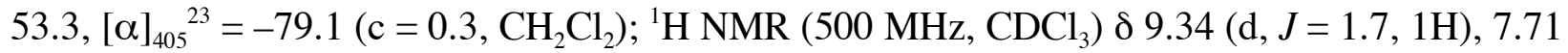
$(\mathrm{d}, J=8.4,2 \mathrm{H}), 7.33(\mathrm{~d}, J=8.0,2 \mathrm{H}), 5.56(\mathrm{ddt}, J=17.9,10.4,6.5,1 \mathrm{H}), 5.13(\mathrm{~s}, 1 \mathrm{H}), 4.88-4.84$

\footnotetext{
${ }^{1}$ A slight modification of our previously reported sequence was employed: Downham, R.; Ng, F. W.; Overman, L. E. J. Org. Chem. 1998, 63, 8096-8097. Modifications included beginning the synthesis with D-diethyl tartrate and substituting allyl bromide for 3-bromo-2-methylpropene in the alkylation step.
} 
$(\mathrm{m}, 2 \mathrm{H}), 4.45(\mathrm{t}, J=4.1,1 \mathrm{H}), 4.34-4.32(\mathrm{~m}, 1 \mathrm{H}), 4.27-4.24(\mathrm{~m}, 1 \mathrm{H}), 3.67(\mathrm{dd}, J=13.0,8.4$, $1 \mathrm{H}), 3.23-3.20(\mathrm{~m}, 1 \mathrm{H}), 3.13(\mathrm{td}, J=12.9,5.0,1 \mathrm{H}), 3.03(\mathrm{~d}, J=9.9,1 \mathrm{H}), 2.64-2.60(\mathrm{~m}, 2 \mathrm{H})$, 2.44-2.41 (m, 4H), 2.22-2.19 (m, 1H), 2.02-2.00 (m, 2H), 1.72-1.69 (m, 1H), 1.57-1.48 (m, 2H), 1.28-1.01 (m, 1H) 0.91-0.84 (m, 1H); $\left.{ }^{13} \mathrm{C} \mathrm{NMR} \mathrm{(125} \mathrm{MHz,} \mathrm{CDCl}{ }_{3}\right) \square$ 196.5, 160.7, 144.3, 137.6, 136.4, 129.9, 127.8, 114.9, 82.7, 60.1, 56.8, 53.3, 53.2, 42.1, 41.6, 39.7, 33.6, 33.4, 29.7, 21.6, 21.5, 21.46; IR (film) 3466, 2934, 2717, 1756, 1640, 1598, 1324, $1158 \mathrm{~cm}^{-1}$; LRMS (ESI) $m / z, 511(\mathrm{M}+\mathrm{Na})^{+}, 489(\mathrm{M}+\mathrm{H})^{+}$. Anal. Calcd for $\mathrm{C}_{25} \mathrm{H}_{32} \mathrm{~N}_{2} \mathrm{O}_{6} \mathrm{~S}: \mathrm{C}, 61.46 ; \mathrm{H}, 6.60 ; \mathrm{N}, 5.73$. Found: C, 61.22; H, 6.62; N, 5.61. This structure was confirmed by COSY, HMQC, and NOESY data.

RCM of Diene 10 and Hydrogenation of the Product to Give Macrocycle 11. A 5-L 3-neck flask was equipped with a magnetic stir bar, a reflux condenser, a gas dispersion tube, and a straight tube adaptor with an in-line Teflon screw seal. A septum was fitted to the straight tube adaptor and a gas flow adaptor, fitted with an argon inlet and an oil bubbler outlet, was placed atop the reflux condenser. The flask was charged with $\mathrm{CH}_{2} \mathrm{Cl}_{2}(3.0 \mathrm{~L})$ and diene 10 (525 $\mathrm{mg}, 0.75 \mathrm{mmol}$ ) and the solution was sparged for $1 \mathrm{~h}$ with a flow of argon through the gas dispersion tube. The solution was heated to reflux and a solution of $\left(\mathrm{PCy}_{3}\right)_{2} \mathrm{Cl}_{2} \mathrm{Ru}=\mathrm{CHPh}(31 \mathrm{mg}$, $0.038 \mathrm{mmol})$ in $\mathrm{CH}_{2} \mathrm{Cl}_{2}(3 \mathrm{~mL})$ was added in one portion through the septum and the Teflon screw was firmly sealed to avoid contact of the solvent vapor with the rubber septum. This solution was heated at reflux for $7 \mathrm{~h}$ under a flow of argon and DMSO $(0.25 \mathrm{~mL})$ then was added. The solution was allowed to cool to rt over $12 \mathrm{~h}$ and filtered through a pad of silica gel with EtOAc $(300 \mathrm{~mL})$, concentrated onto Celite and this residue was purified by flash chromatography on silica using a gradient solvent system (1:100 EtOAc:benzene, then 1:50 EtOAc:benzene then, 1:20 EtOAc:benzene, then 1:10 EtOAc:benzene, then 1:5 EtOAc:benzene) to provide the RCM product, a 1:2 mixture of $E$ and $Z$ stereoisomers, as a slightly yellow foam (377 mg, $0.56 \mathrm{mmol}, 75 \%$ ). This product could not be stored neat because of decomposition; thus, it was directly hydrogenated. Separation of these isomers proved difficult so they were characterized together; diagnostic data: $\mathrm{R}_{\mathrm{f}}=0.55$, 1:9 EtOAc:benzene, ${ }^{1} \mathrm{H}$ NMR $(500 \mathrm{MHz}$, $\mathrm{CDCl}_{3}$ ) $\square$ 5.40-5.34 (overlapping, $\mathrm{m}, 1 \mathrm{H}$ ), 5.30-5.23 (overlapping, $\mathrm{m}, 1 \mathrm{H}$ ), 4.34 (dd, $J=8.4,2.0$, $0.33 \mathrm{H}), 4.41(\mathrm{dd}, J=6.9,2.1,0.67 \mathrm{H}), 3.97$ (overlapping, $\mathrm{m}, 1 \mathrm{H}), 3.87(\mathrm{~d}, J=9.5,0.33 \mathrm{H})$, 3.80-3.75 (overlapping m, $1.67 \mathrm{H}), 3.61(\mathrm{~d}, J=9.7,0.67 \mathrm{H}), 3.51(\mathrm{~d}, J=9.5,0.33 \mathrm{H}), 3.41$ (overlapping apt $\mathrm{dd}, J=10.3,5.2,1 \mathrm{H}$ ), 3.03-2.92 (overlapping $\mathrm{m}, 3.66 \mathrm{H}$ ), 2.42-2.39 (overlapping $\mathrm{m}, 3.66 \mathrm{H}$ ), 2.35-2.13 (overlapping m, $1.33 \mathrm{H}$ ), 2.03-1.95 (overlapping $\mathrm{m}, 3 \mathrm{H}$ ), 1.66-1.10 (overlapping m, $13 \mathrm{H}$ ), 1.09-1.02 (overlapping peaks, $18 \mathrm{H}), 0.90(\mathrm{~s}, 9 \mathrm{H}), 0.75$ (s, $6 \mathrm{H}) ;{ }^{13} \mathrm{C} \mathrm{NMR}\left(125 \mathrm{MHz}, \mathrm{CDCl}_{3}\right) \square 162.1,130.4,98.2,83.6,83.4,69.3 .69 .2,66.2,63.2,62.8$, 62.4, 62.0, 59.1, 59.0, 54.5, 54.8, 43.5, 43.4, 43.0, 41.9, 41.4, 41.3, 404, 38.2, 37.7, 32.9, 29.7, $28.2,26.9,26.8,25.9+, 25.9,24.6,22.6,21.9,21.8,21.5,18.4,18.3,18.2,13.7,12.2,-5.2,-5.3$, -5.4 (not all peaks for the two isomers are resolved); LRMS (ESI) $\mathrm{m} / z .1372(2 \mathrm{M}+\mathrm{Na})^{+}, 1350$ $(2 \mathrm{M}+\mathrm{H})^{+}, 697(\mathrm{M}+\mathrm{Na})^{+}, 675(\mathrm{M}+\mathrm{H})^{+}$.

Palladium on carbon (180 mg, 10\% Degüssa Type) was added to a degassed solution of the RCM product $(377 \mathrm{mg}, 0.56 \mathrm{mmol})$ in EtOAc $(4.5 \mathrm{~mL})$. The reactor was evacuated and backfilled with $\mathrm{H}_{2}$ from a balloon and the suspension was stirred under a $\mathrm{H}_{2}$ atmosphere for $6 \mathrm{~h}$. The reaction mixture was filtered through Celite with the aid of EtOAc $(20 \mathrm{~mL})$ and concentrated. The resulting residue was purified by column chromatography on silica gel (1:9, EtOAc:benzene) to give a macrocycle 11 as a colorless foam $(340 \mathrm{mg}, 0.50 \mathrm{mmol}, 93 \%, 70 \%$ 
over the two steps): $[\square]_{\mathrm{D}}^{23}=+9.9$, $[\square]_{577}{ }^{23}=+9.9,[\square]_{546}^{23}=+11.2,[\square]_{435}{ }^{23}=+14.5,[\square]_{405}{ }^{23}=$ $+15.6\left(\mathrm{c}=0.21, \mathrm{CH}_{2} \mathrm{Cl}_{2}\right) ;{ }^{1} \mathrm{H} \operatorname{NMR}\left(500 \mathrm{MHz}, \mathrm{CDCl}_{3}\right) \square 4.40(\mathrm{t}, J=2.7,1 \mathrm{H}), 4.01(\mathrm{dd}, J=11.5$, $3.0,1 \mathrm{H}), 3.92(\mathrm{dd}, J=11.4,2.5,1 \mathrm{H}), 3.88(\mathrm{~d}, J=10.3,1 \mathrm{H}), 3.50(\mathrm{~d}, J=10.3,1 \mathrm{H}), 3.40(\mathrm{dd}, J=$ 9.6, 5.2 $1 \mathrm{H}), 3.13(\mathrm{~d}, J=10.3,1 \mathrm{H}), 3.07-2.95(\mathrm{~m}, 3 \mathrm{H}), 2.60-2.51(\mathrm{~m}, 2 \mathrm{H}), 2.46-2.42(\mathrm{~m}, 1 \mathrm{H})$, 2.05-1.99 (m, 1H), 1.95-1.88 (m, 2H), 1.80-1.75 (m, 1H), 1.62-1.56 (m, 3H), 1.46-1.41 (m, $8 \mathrm{H}), 1.27-1.21(\mathrm{~m}, 9 \mathrm{H}), 1.09-1.05(\mathrm{~m}, 22 \mathrm{H}) 0.10(\mathrm{~s}, 3 \mathrm{H}), 0.08(\mathrm{~s}, 3 \mathrm{H}), ;{ }^{13} \mathrm{C}$ NMR $(125 \mathrm{MHz}$, $\left.\mathrm{CDCl}_{3}\right) \square 163.0,81.8,68.9$. 64.8, 61.8, 61.5, 59.1, 54.9, 45.1, 41.5, 41.1, 40.9, 36.7, 33.7, 28.0, 27.1, 26.4, 25.9, 25.5, 24.7, 24.4, 23.6, 22.2, 20.4, 18.3, 18.2, 12.3, -5.4, -5.6; IR (film) 2935, 2866, 1753, $\mathrm{cm}^{-1}$ LRMS (ESI) $m / z, 1375(2 \mathrm{M}+\mathrm{Na})^{+}, 701(\mathrm{M}+\mathrm{Na})^{+}, 677(\mathrm{M}+\mathrm{H})^{+}$. Anal. Calcd for $\mathrm{C}_{38} \mathrm{H}_{72} \mathrm{~N}_{2} \mathrm{O}_{4} \mathrm{Si}_{2}: \mathrm{C}, 67.40 ; \mathrm{H}, 10.72 ; \mathrm{N}, 4.14$. Found $\mathrm{C}, 67.49 ; \mathrm{H}, 10.81 ; \mathrm{N}, 4.16$.

Condensation of 13 and 14 to Give 1,3-Oxazocane 15. Amino diol 13 (40 mg, 0.08 $\mathrm{mmol})$ and aldehyde $14(50 \mathrm{mg}, 0.20 \mathrm{mmol})$ were dissolved in benzene $(2.5 \mathrm{~mL})$, shielded from light and heated to reflux using a Dean-Stark trap to remove water. After $18 \mathrm{~h}$, the reaction mixture was allowed to cool to $\mathrm{rt}$ and the benzene solution was placed directly on a silica gel column. Flash chromatography (20:80:2, EtOAc:hex:Et $\left.{ }_{3} \mathrm{~N}\right)$ gave aminal 15 (48 $\mathrm{mg}$, 89\%) as a colorless foam: ${ }^{1} \mathrm{H}$ NMR $\left(500 \mathrm{MHz}, \mathrm{CDCl}_{3}\right) \square 7.31(\mathrm{~d}, J=8.4,2 \mathrm{H}), 6.88(\mathrm{~d}, J=8.4,2 \mathrm{H}), 6.21$ $(\mathrm{dt}, J=7.3,1.3,1 \mathrm{H}), 6.13(\mathrm{dt}, J=7.1,6.7,1 \mathrm{H}), 5.50-5.41(\mathrm{~m}, 1 \mathrm{H}), 5.38-5.31(\mathrm{~m}, 1 \mathrm{H}), 4.71(\mathrm{~d}, J$ $=11.2,1 \mathrm{H}), 4.45(\mathrm{~d}, J=11.2,1 \mathrm{H}), 4.14(\mathrm{dd}, J=7.8,4.9,1 \mathrm{H}), 3.92(\mathrm{dd}, J=11.6,2.9,1 \mathrm{H}), 3.81$ (s, 3H), 3.68-3.64 (m, 2H), $3.33(\mathrm{~d}, J=11.8,1 \mathrm{H}), 3.28(\mathrm{~d}, J=11.8,1 \mathrm{H}), 3.14(\mathrm{~d}, J=9.3,1 \mathrm{H})$, $3.09(\mathrm{~s}, 1 \mathrm{H}), 3.06-3.02(\mathrm{~m}, 1 \mathrm{H}), 2.86(\mathrm{t}, J=6.8,2 \mathrm{H}), 2.79-2.62(\mathrm{~m}, 3 \mathrm{H}), 2.60-2.57(\mathrm{~m}, 1 \mathrm{H})$, 2.20-1.97 (m, 4H), 1.95-1.94 (m, 1H), 1.77-1.12 (m, 23H); ${ }^{13} \mathrm{C} \mathrm{NMR}\left(125 \mathrm{MHz}, \mathrm{CDCl}_{3}\right) \square$ 159.0, 139.8, 131.5, 131.2, 129.2, 125.0, 113.8, 87.3, 85.1, 82.4, 80.2, 70.7, 68.5, 65.5, 59.4, 59.1, 55.3, 50.1, 43.8, 42.6, 41.0, 39.2, 38.4, 38.3, 36.6, 33.4, 27.7, 26.9, 25.7, 25.4, 25.0, 24.2, 23.8, 22.3, 21.7; LRMS (ESI) $\mathrm{m} / z, 755(\mathrm{M}+\mathrm{Na})^{+}, 733(\mathrm{M}+\mathrm{H})^{+}$; this structure was confirmed by COSY, HMQC, and HMBC data.

Reduction of 15 to Give Rearrangement Product 16. A solution of aldehyde 14 (47 $\mathrm{mg}, 0.19 \mathrm{mmol})$, amino diol $13(37 \mathrm{mg}, 0.075 \mathrm{mmol})$ and benzene $(1.8 \mathrm{~mL})$ was shielded from light and heated at reflux for $14 \mathrm{~h}$ using a Dean-Stark apparatus topped with a $\mathrm{CaCl}_{2}$ drying tube. The reaction mixture was concentrated, and the resulting residue of crude $\mathbf{1 5}$ was suspended in MeCN (1.0 mL). Sodium cyanoborohydride $(70 \mathrm{mg}, 1.13 \mathrm{mmol})$ was added and the reaction mixture was stirred vigorously until consumption of aldehyde 14 was complete, as judged by TLC. Methylene chloride $(1.0 \mathrm{~mL})$ and $\mathrm{AcOH}(0.04 \mathrm{~mL})$ then were added, followed by a second charge of $\mathrm{NaBH}_{3} \mathrm{CN}$ (70 mg, $1.1 \mathrm{mmol}$ ). The suspension was vigorously stirred for $12 \mathrm{~h}$, then diluted with $\mathrm{CH}_{2} \mathrm{Cl}_{2}(25 \mathrm{~mL})$, and washed with aqueous phosphate buffer $(\mathrm{pH}=8)$. The aqueous portion was back-extracted with $\mathrm{CH}_{2} \mathrm{Cl}_{2}(4 \square 10 \mathrm{~mL})$. The combined organic portions were washed with brine $(2 \square 20 \mathrm{~mL})$, dried over $\mathrm{Na}_{2} \mathrm{SO}_{4}$, and concentrated. Purification of the residue by column chromatography on silica gel using a gradient solvent system (10:36:1 EtOAc:hex:Et ${ }_{3} \mathrm{~N}$, then 40:9:1 EtOAc:hex:Et ${ }_{3} \mathrm{~N}$ ) gave 16 as a viscous oil (47 $\mathrm{mg}, 0.064 \mathrm{mmol}$,

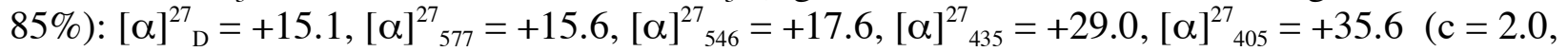
$\left.\mathrm{CHCl}_{3}\right) ;{ }^{1} \mathrm{H}$ NMR $\left(500 \mathrm{MHz}, \mathrm{CDCl}_{3}, 318 \mathrm{~K}\right) \square 7.18(\mathrm{~d}, J=8.6,2 \mathrm{H}), 6.86(\mathrm{~d}, J=8.6,2 \mathrm{H}), 6.21$ $(\mathrm{d}, J=7.3,1 \mathrm{H}), 6.14(\mathrm{dd}, J=13.9,6.91 \mathrm{H}), 5.49-5.45(\mathrm{~m}, 1 \mathrm{H}), 5.41-5.36(\mathrm{~m}, 1 \mathrm{H}), 4.42($ app s, $2 \mathrm{H}), 4.24-4.20(\mathrm{~m}, 1 \mathrm{H}), 3.84-3.77(\mathrm{~m}, 6 \mathrm{H}), 3.75(\mathrm{~m}, 1 \mathrm{H}), 3.45(\mathrm{~d}, J=11.4,1 \mathrm{H}), 3.34(\mathrm{~m}, 1 \mathrm{H})$, $3.11(\mathrm{~m}, 1 \mathrm{H}), 3.04-2.29(\mathrm{~m}, 5 \mathrm{H}), 2.60-2.50(\mathrm{~m}, 2 \mathrm{H}), 2.34-2.25(\mathrm{~m}, 4 \mathrm{H}), 2.16-2.08(\mathrm{~m}, 1 \mathrm{H})$, 2.06-1.98 (m, 1H), 1.97-1.91 (m, 3H), $1.90(\mathrm{t}, J=9.6,1 \mathrm{H}), 1.52-1.33(\mathrm{~m}, 18 \mathrm{H}), 1.24-1.19(\mathrm{~m}$, 
1H), 1.18-1.09 (m, 1H); ${ }^{13} \mathrm{C}$ NMR (125 MHz, $\left.\mathrm{CDCl}_{3}, 318 \mathrm{~K}\right) \square$ 159.2, 139.5, 131.4, 130.2, 129.2, 125.1, 113.7, 82.4, 79.2, 77.1, 73.5, 72.0, 70.3, 69.5, 55.3, 54.9, 51.2, 48.9, 39.4, 39.0, $35.7,33.4,32.8,31.7,27.7,26.5,26.2,25.9,25.89,25.3,24.7,24.4,23.1,22.7,21.4$ (two carbons observed at 49.8 are not resolved, see HMQC); IR (film) 3512, 2929, 2860, 1611, 1586 $\mathrm{cm}^{-1}$; LRMS (ESI) $\mathrm{m} / z, 757(\mathrm{M}+\mathrm{Na})^{+}, 735(\mathrm{M}+\mathrm{H})^{+}$; HRMS (ESI) $m / z$ 735.3615 (735.3598 calcd for $\left.\mathrm{C}_{38} \mathrm{H}_{59} \mathrm{IN}_{2} \mathrm{O}_{4},(\mathrm{M}+\mathrm{H})^{+}\right)$; this structure was confirmed by COSY, HMQC, and HMBC data.

Reductive Amination of 13 to Give 17. A solution of amino diol 13 (40 $\mathrm{mg}, 0.08$ mmol), aldehyde $14(50 \mathrm{mg}, 0.20 \mathrm{mmol})$ and benzene $(2.5 \mathrm{~mL})$ was shielded from light and heated to reflux using a Dean-Stark trap to remove $\mathrm{H}_{2} \mathrm{O}$. After $18 \mathrm{~h}$, the reaction mixture was allowed to cool to rt and benzene was removed by rotary evaporation. Crude $\mathbf{1 5}$ was dissolved in toluene $(2.0 \mathrm{~mL})$, this solution was cooled to $-78^{\circ} \mathrm{C}$, diisobutylaluminum hydride $(260 \square \mathrm{L}, 1.5$ $\mathrm{M}$ in toluene, $0.40 \mathrm{mmol}$ ) was added. The reaction was maintained at $-78^{\circ} \mathrm{C}$ for $30 \mathrm{~min}$, and then quenched by addition of a saturated solution of sodium potassium tartrate $(2 \mathrm{~mL})$ and EtOAc $(2$ $\mathrm{mL})$. This mixture was stirred for $2 \mathrm{~h}$ and the aqueous layer was extracted with EtOAc (3ฤ5 mL) and $\mathrm{CH}_{2} \mathrm{Cl}_{2}(3 \square 5 \mathrm{~mL})$. The combined organic extracts were dried $\left(\mathrm{MgSO}_{4}\right)$ and concentrated. The crude product was purified by flash chromatography (EtOAc:Hex, 1:1) to give 17 (41 mg, $71 \%$ ) as an oil: $[\square]_{405}{ }^{23}=-102,[\square]_{435}{ }^{23}=-84.9,[\square]_{546}{ }^{23}=-50.0,[\square]_{577}{ }^{23}=-39.5,[\square]_{\mathrm{D}}{ }^{23}=-39.7(\mathrm{c}$ $\left.=0.3, \mathrm{CH}_{2} \mathrm{Cl}_{2}\right) ;{ }^{1} \mathrm{H}$ NMR $\left(500 \mathrm{MHz}, \mathrm{CDCl}_{3}\right) \square 7.29(\mathrm{~d}, \mathrm{~J}=8.5,2 \mathrm{H}), 6.89(\mathrm{~d}, \mathrm{~J}=8.5,2 \mathrm{H}), 6.20$ $(\mathrm{d}, \mathrm{J}=7.3,1 \mathrm{H}), 6.13-6.09(\mathrm{~m}, 1 \mathrm{H}), 5.42-5.37(\mathrm{~m}, 1 \mathrm{H}), 5.34-5.29(\mathrm{~m}, 1 \mathrm{H}), 4.79(\mathrm{~d}, \mathrm{~J}=11.1$, $1 \mathrm{H}), 4.40(\mathrm{~d}, \mathrm{~J}=11.1,1 \mathrm{H}), 4.12-4.10(\mathrm{~m}, 1 \mathrm{H}), 3.90-3.88(\mathrm{~m}, 1 \mathrm{H}), 3.82(\mathrm{~s}, 3 \mathrm{H}), 3.76-3.74(\mathrm{~m}$, $1 \mathrm{H}), 3.56(\mathrm{~d}, \mathrm{~J}=11.1,1 \mathrm{H}), 3.49(\mathrm{~d}, \mathrm{~J}=11.2,1 \mathrm{H}), 3.17-3.15(\mathrm{~m}, 2 \mathrm{H}), 2.89-2.60(\mathrm{~m}, 11 \mathrm{H}), 2.18-$ $2.14(\mathrm{~m}, 2 \mathrm{H}), 2.05-1.99(\mathrm{~m}, 3 \mathrm{H}), 1.74-1.15(\mathrm{~m} 23 \mathrm{H}) ;{ }^{13} \mathrm{C} \mathrm{NMR}\left(125 \mathrm{MHz}, \mathrm{CDCl}_{3}\right) \square 159.1$, 139.6, 131.5, 131.2, 128.8, 128.3, 125.1, 113.8, 82.2, 81.8, 71.1, 70.3, 69.7, 60.8, 60.7, 59.2, 58.6, 55.3, 51.8, 43.9, 42.7, 41.0, 39.9, 38.6, 37.6, 33.5, 29.3, 27.9, 26.7, 25.9, 25.8, 25.6, 25.5, 24.4, 24.3, 22.8, 22.3; IR (film) 3374, 2922, 2857, 1613, 1514, 1246, $1035 \mathrm{~cm}^{1}$; HRMS (ESI) $\mathrm{m} / \mathrm{z} 735.3583\left(735.3598\right.$ calcd for $\left.\mathrm{C}_{38} \mathrm{H}_{60} \mathrm{IN}_{2} \mathrm{O}_{4},(\mathrm{M}+\mathrm{H})_{+}\right)$; the structure was further confirmed by COSY, HMQC, and HMBC data. 


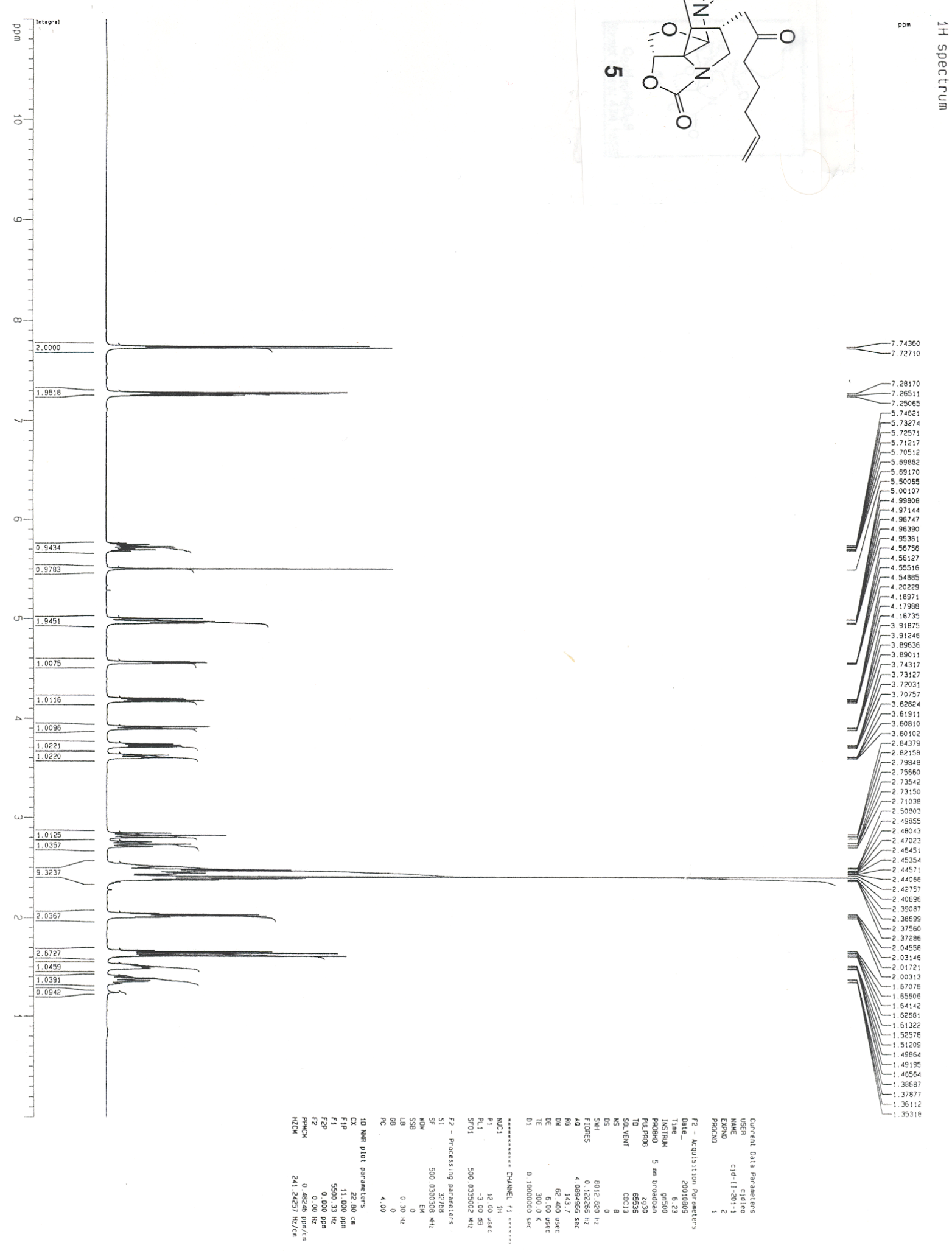



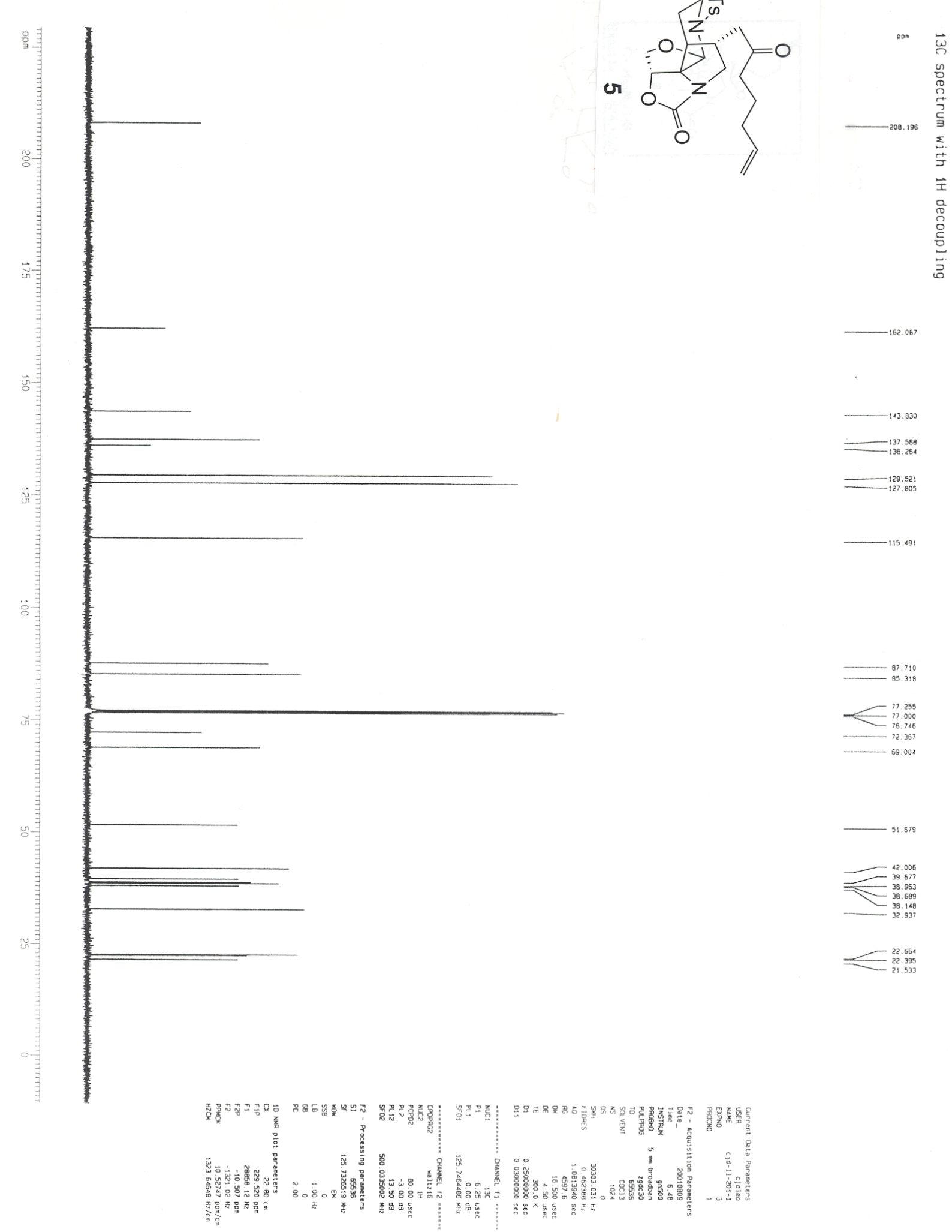

$-51.679$

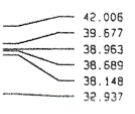

$\left[\begin{array}{r}22.654 \\ 22.995 \\ 21.533\end{array}\right.$ 


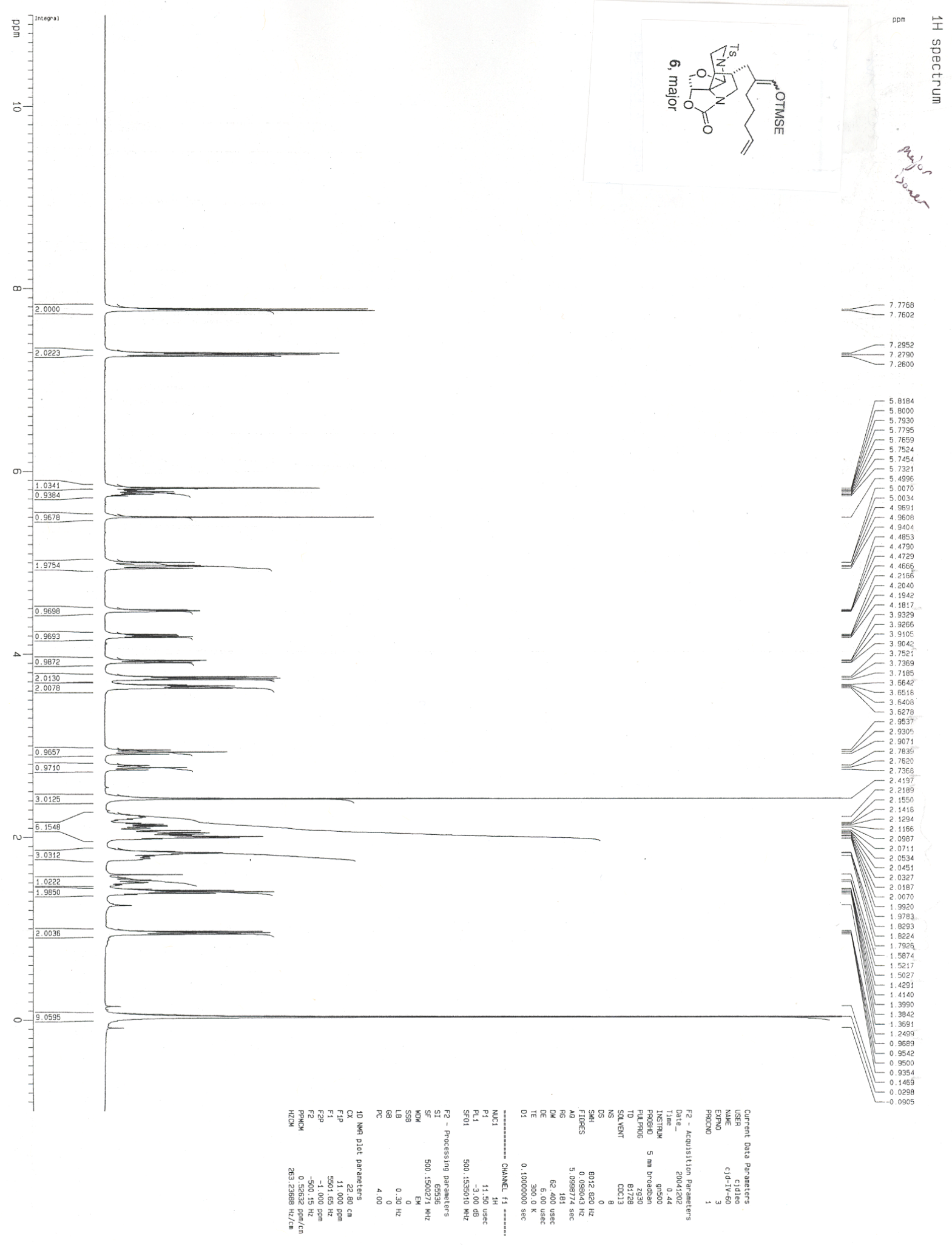


S8

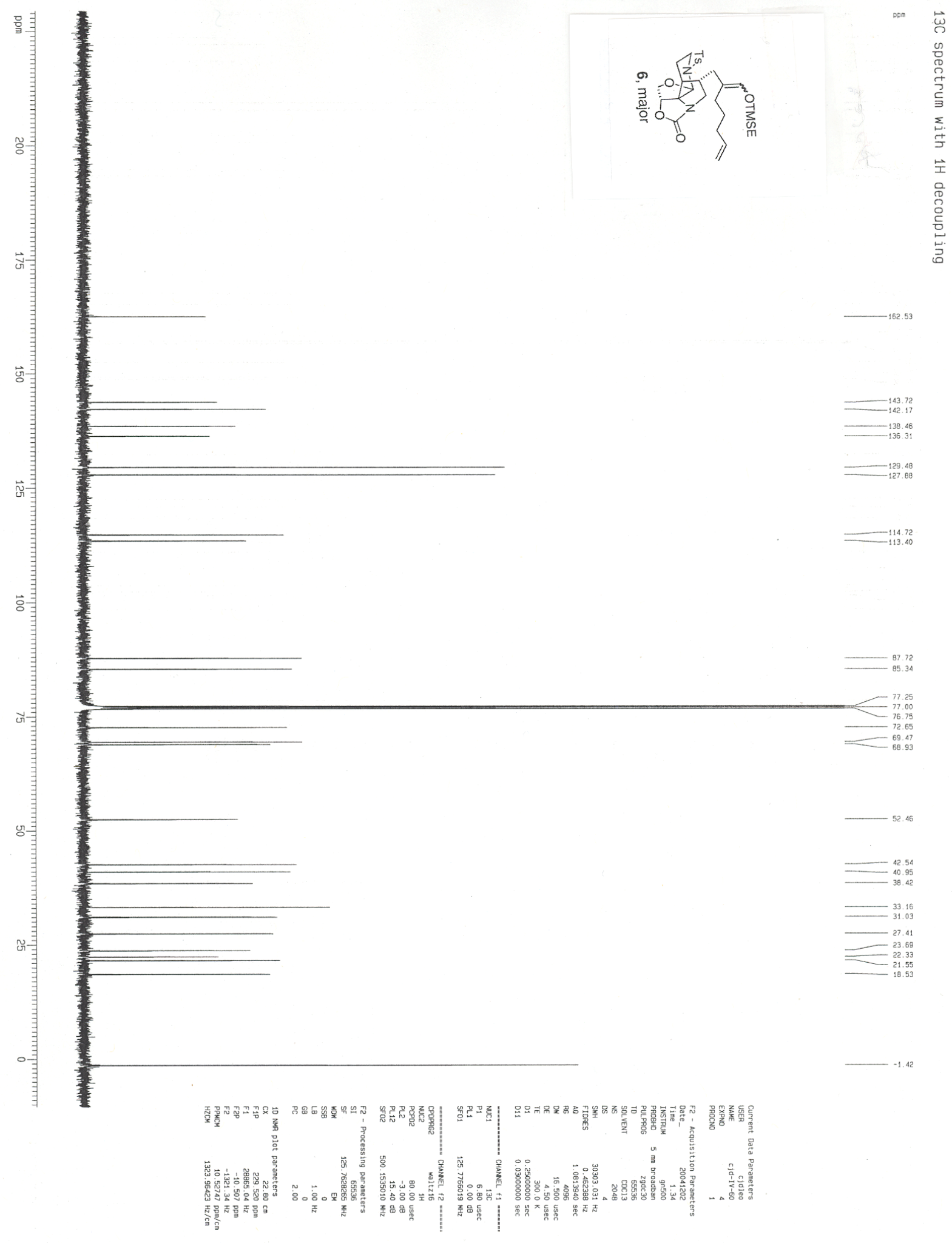


S9

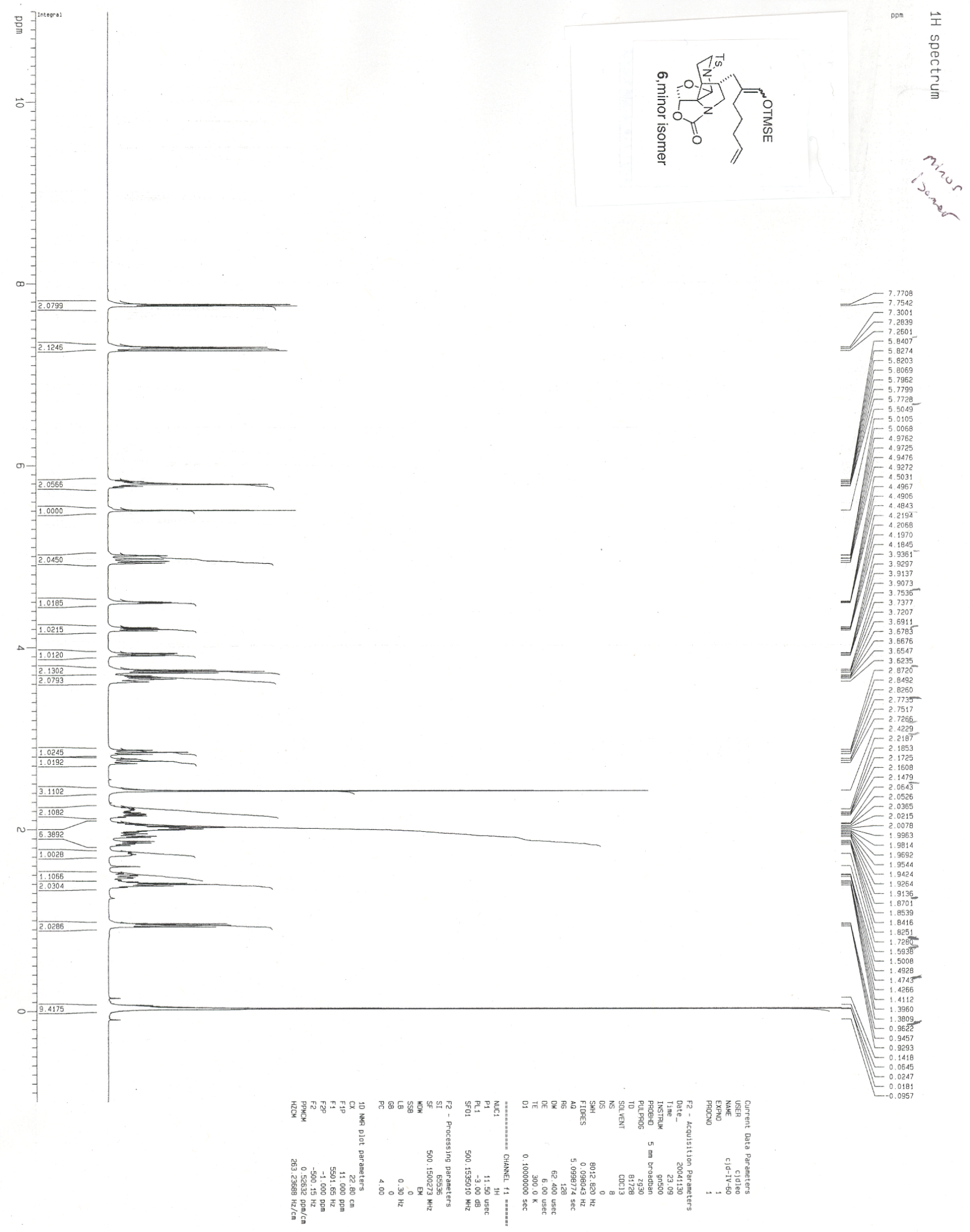




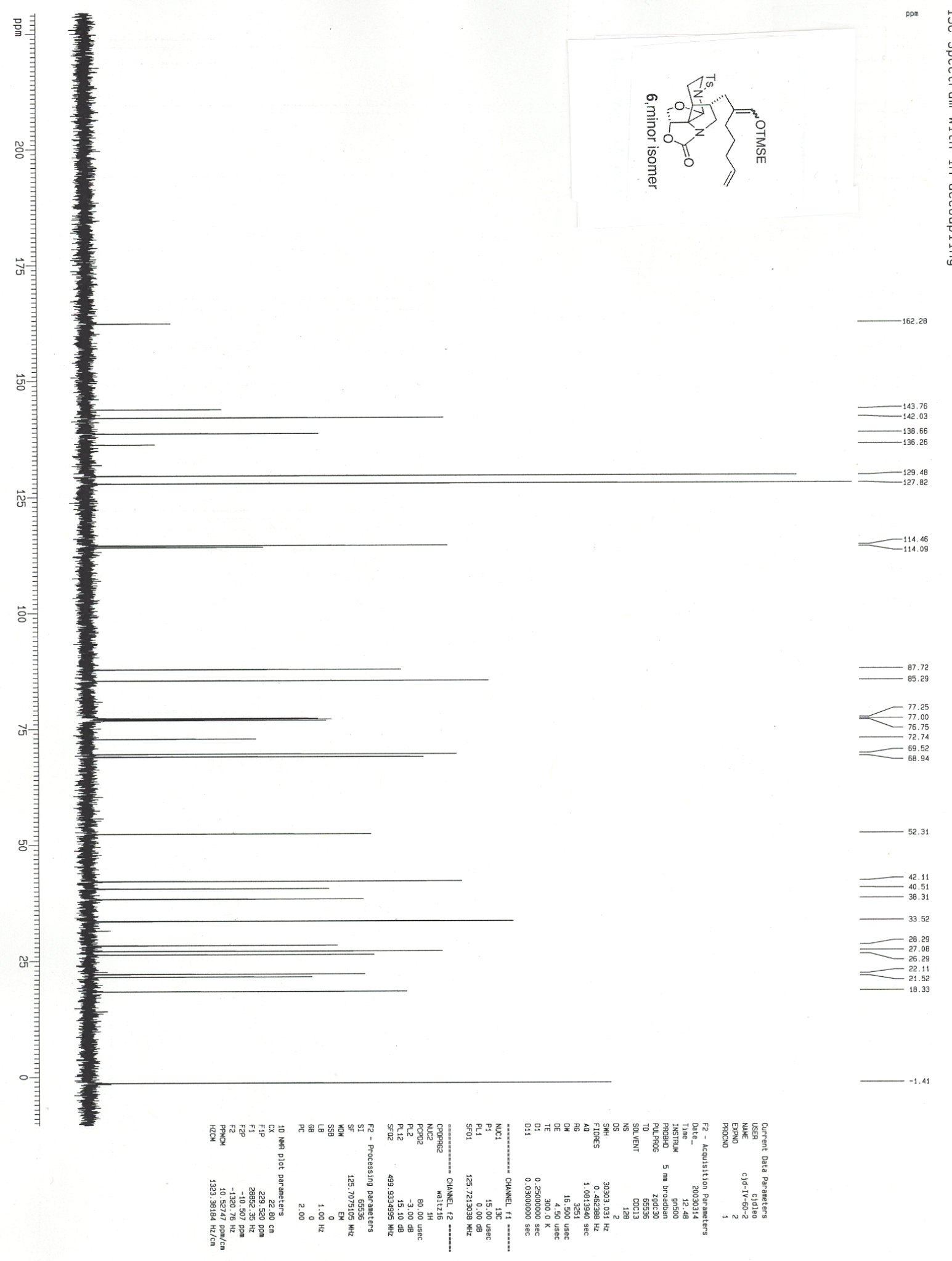


S11
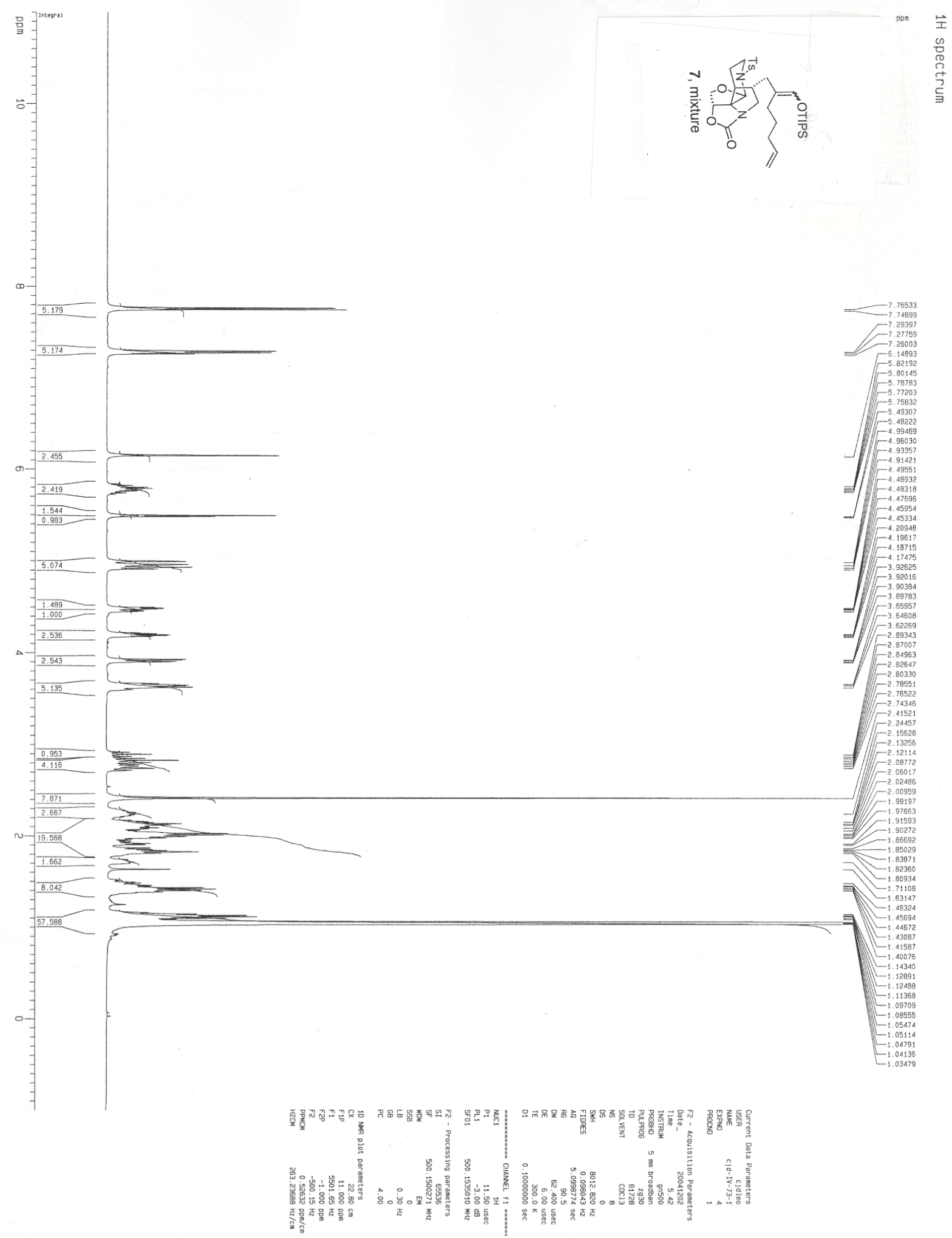


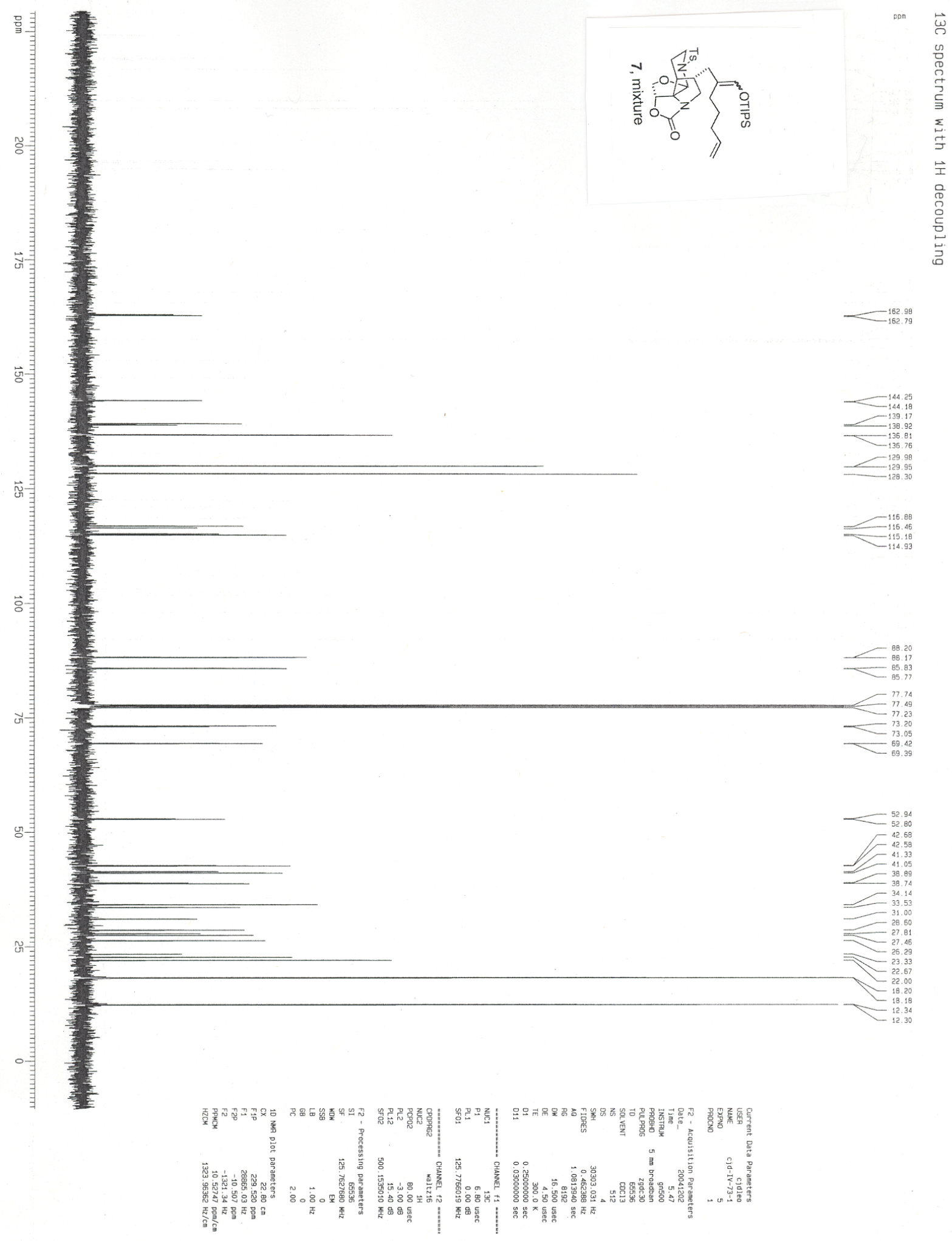


S13

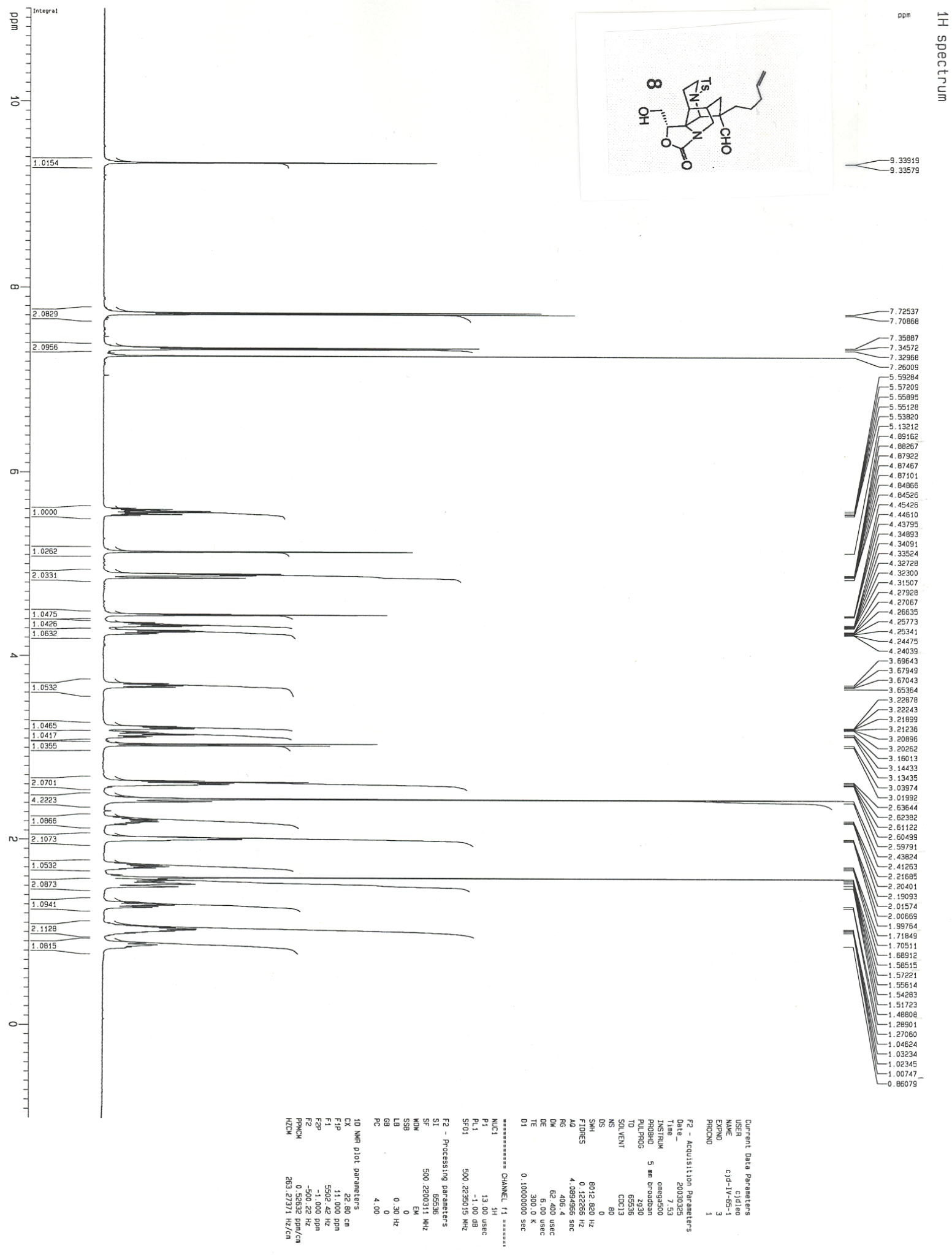




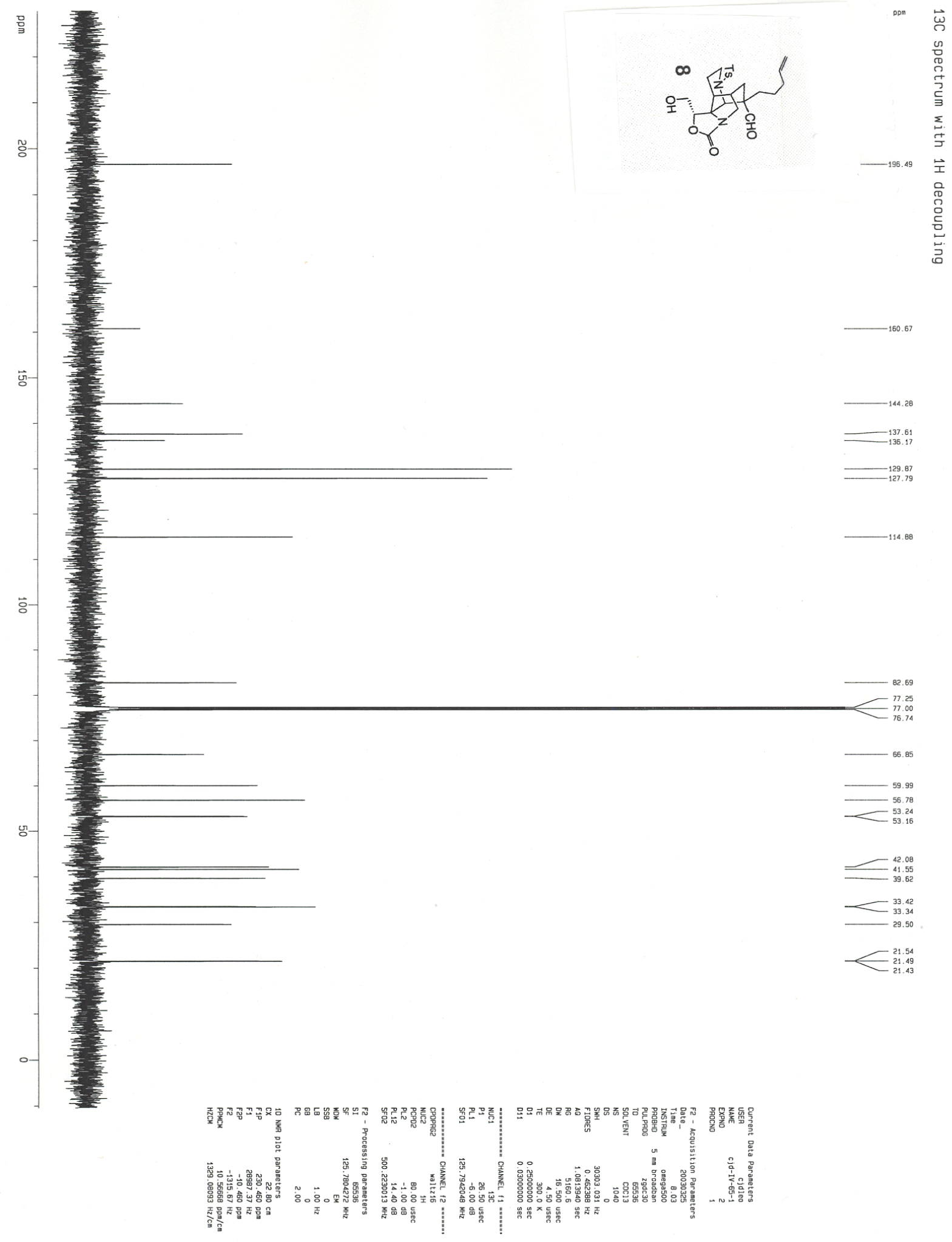




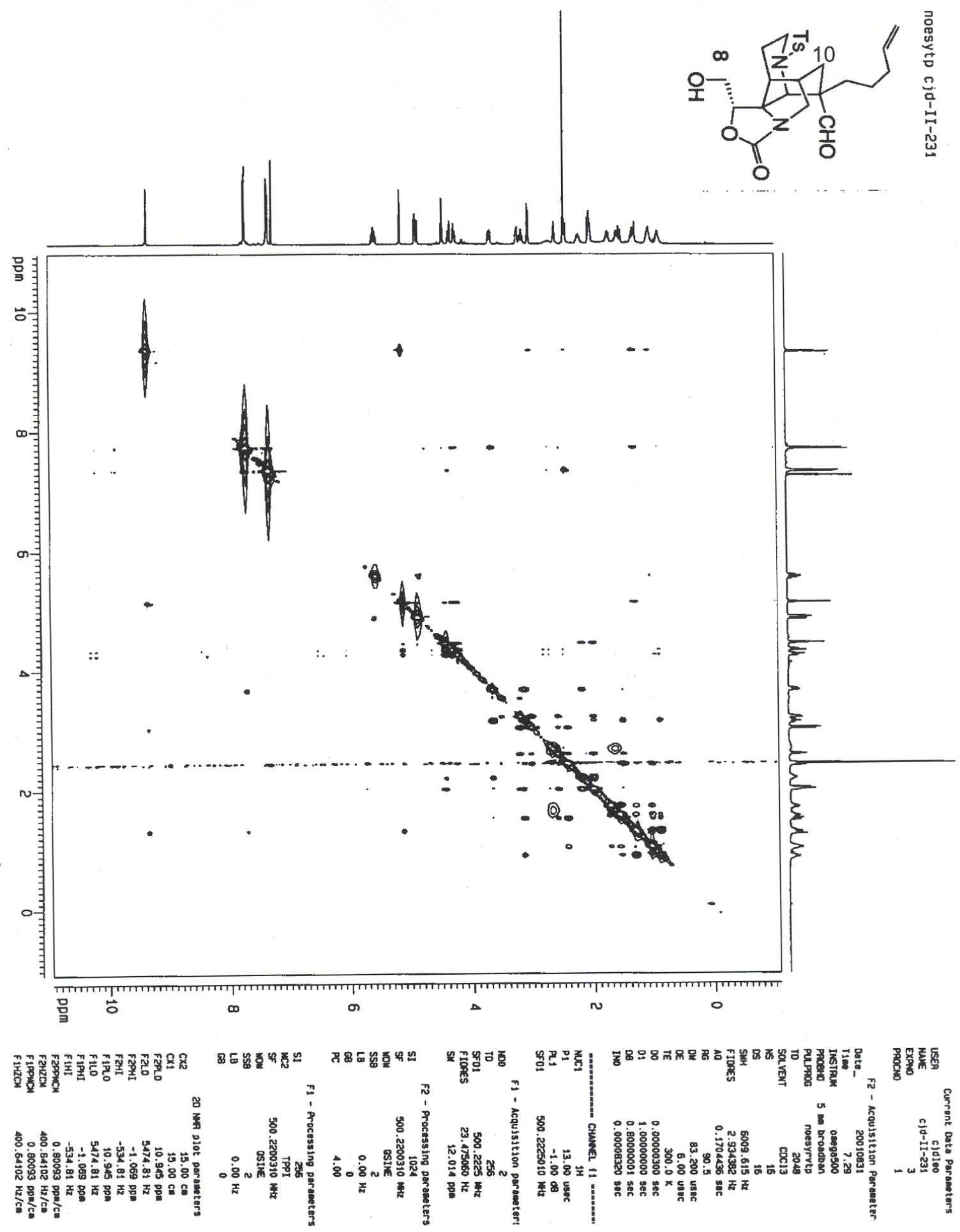




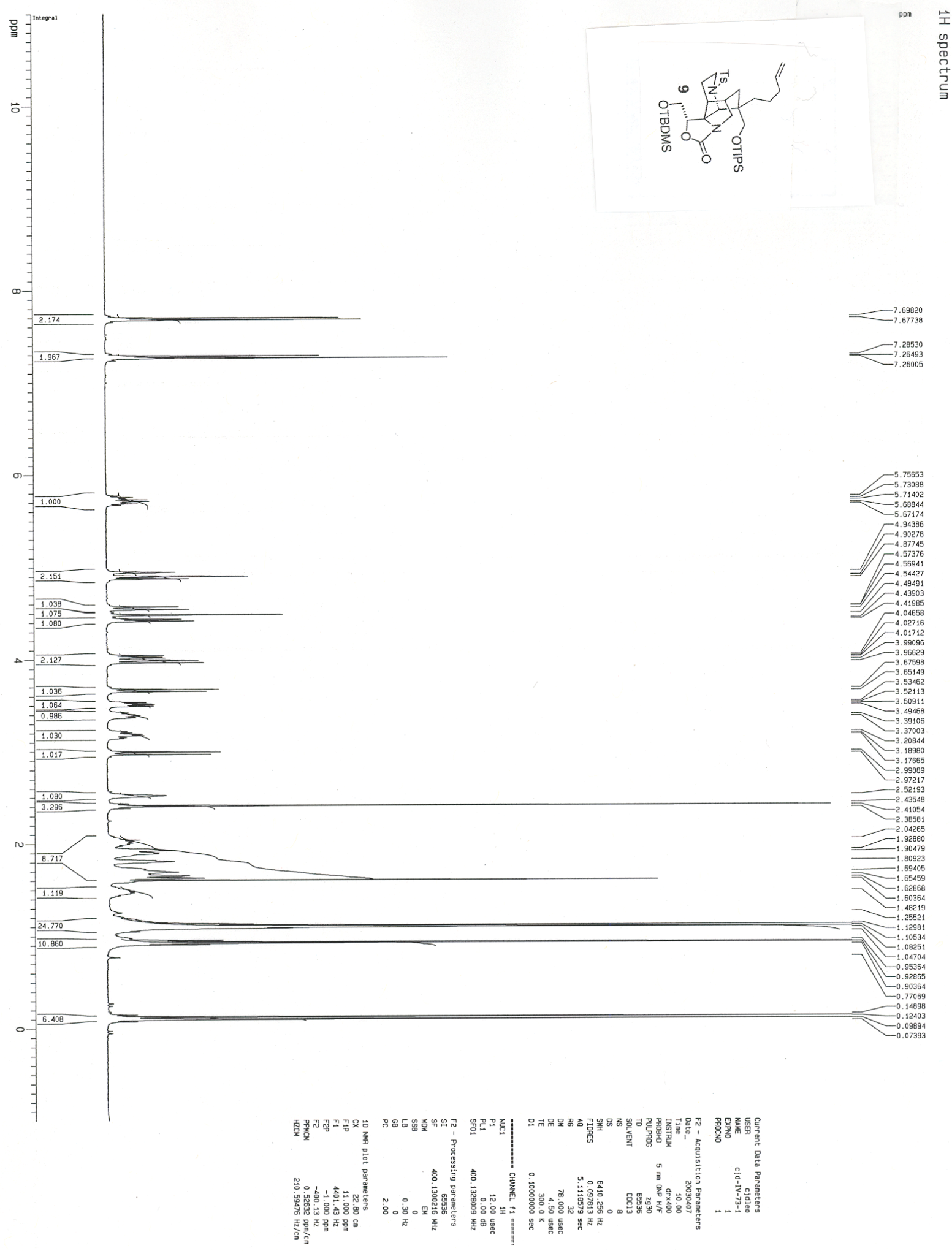




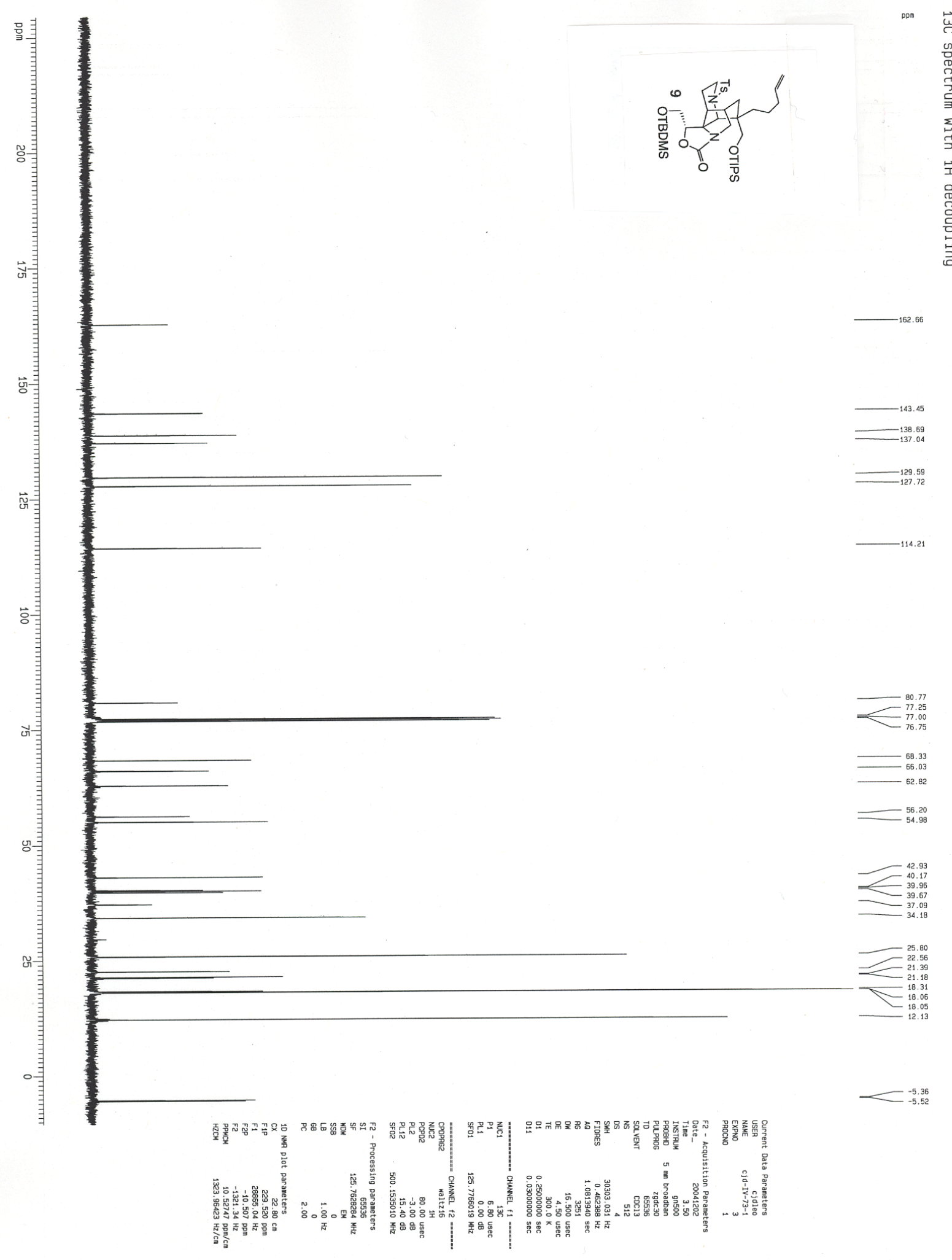


S18

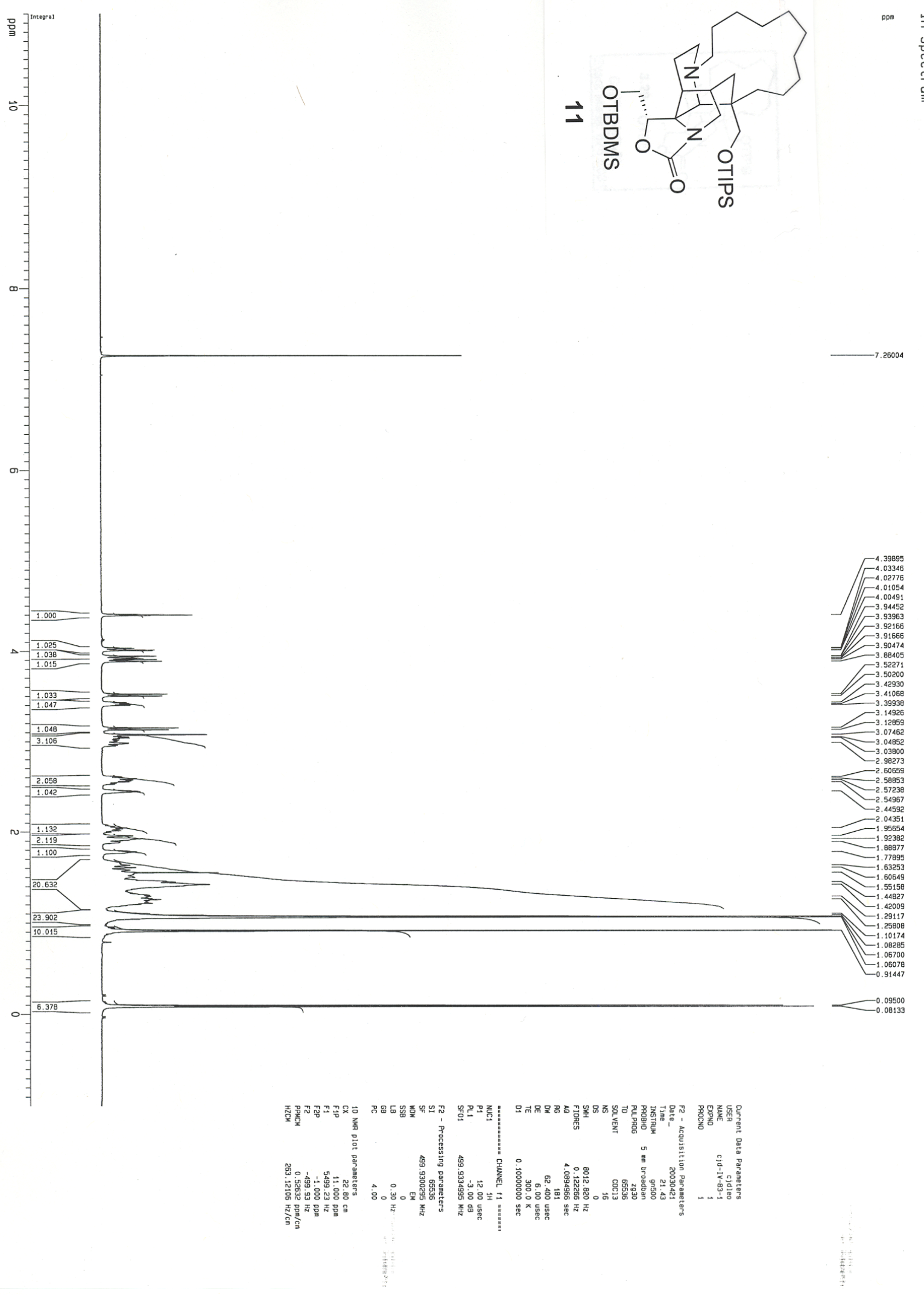


S19
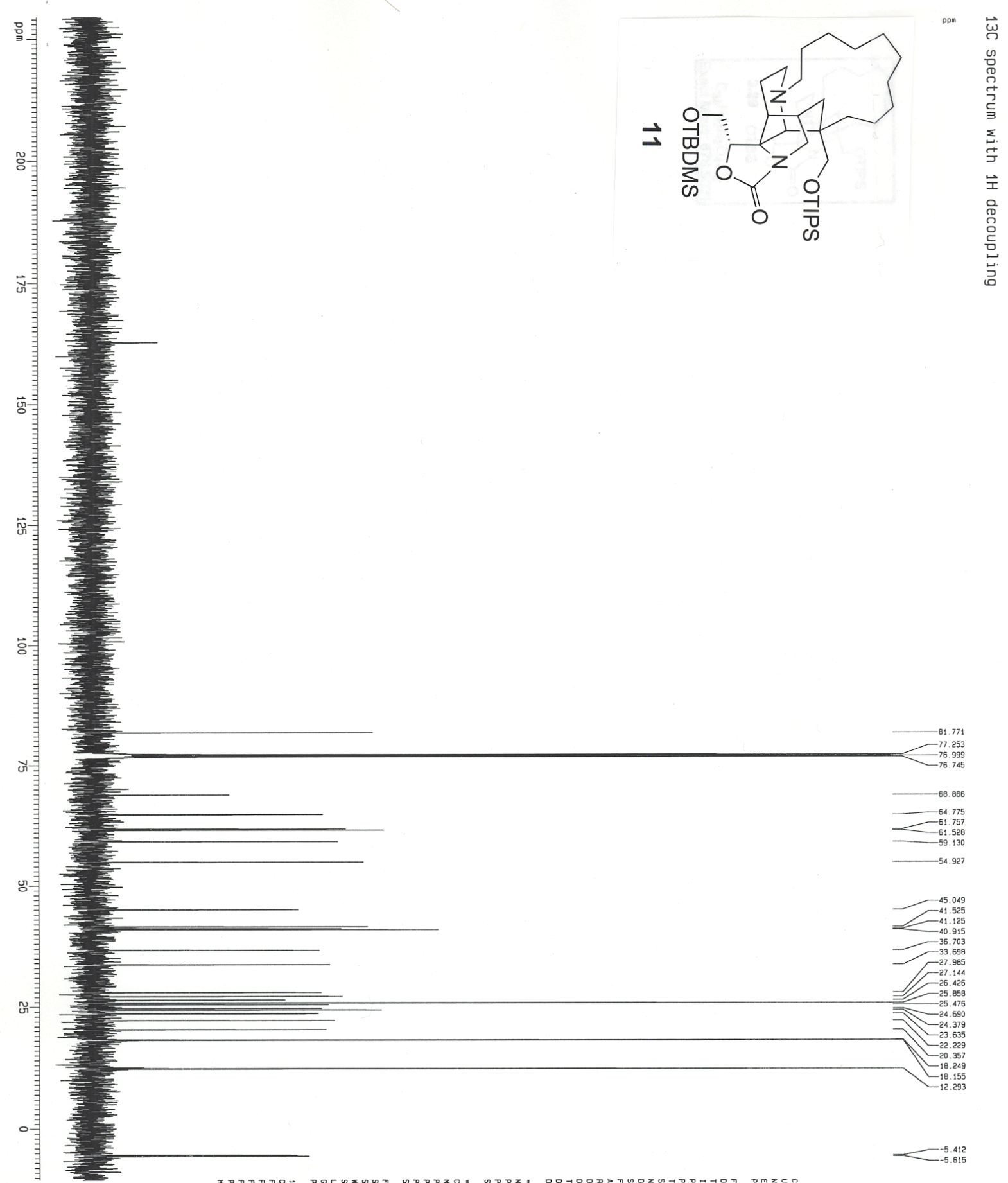

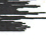

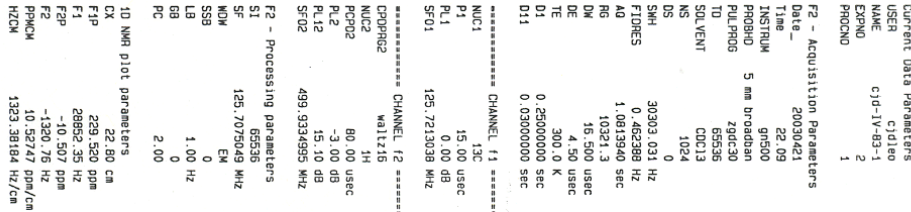




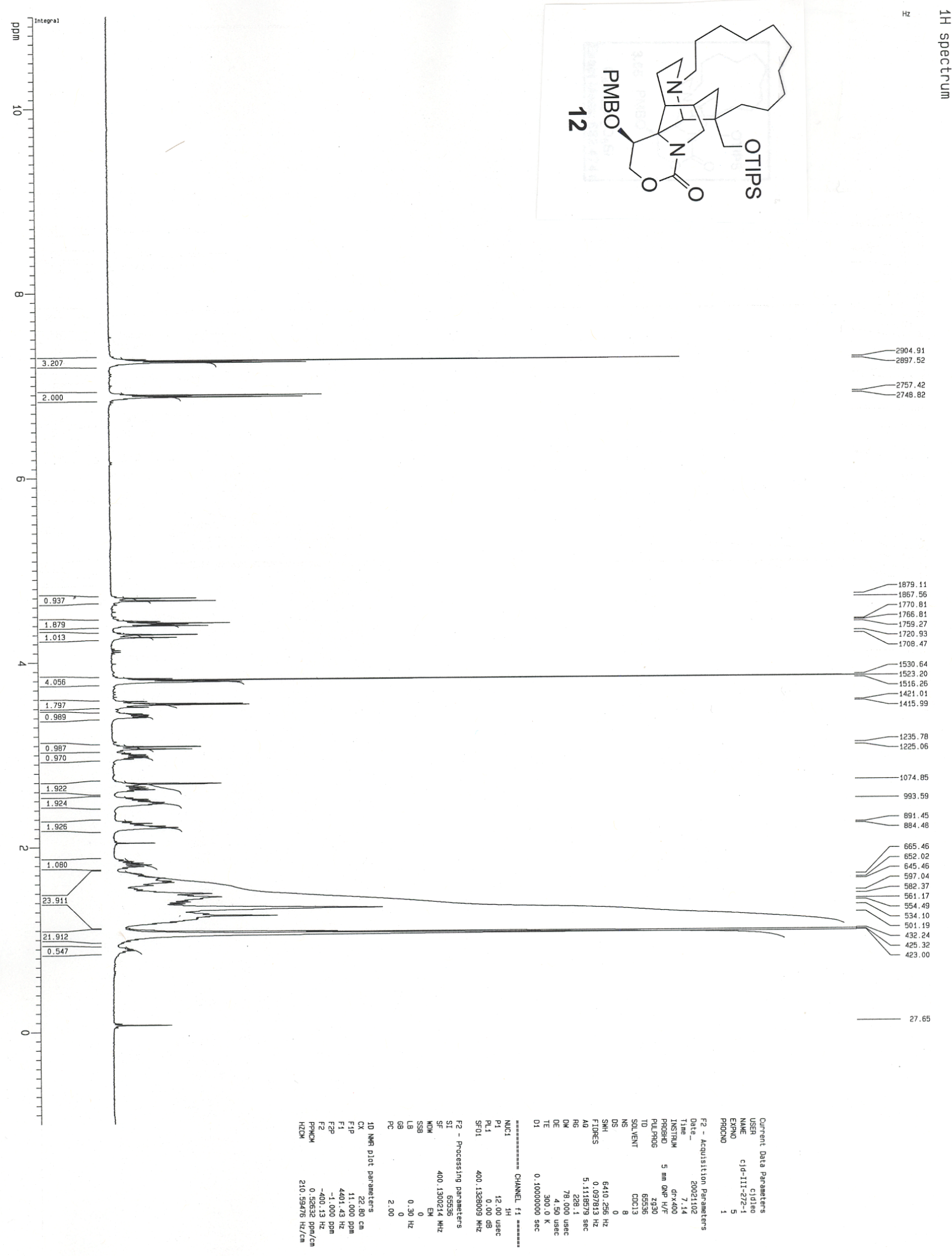




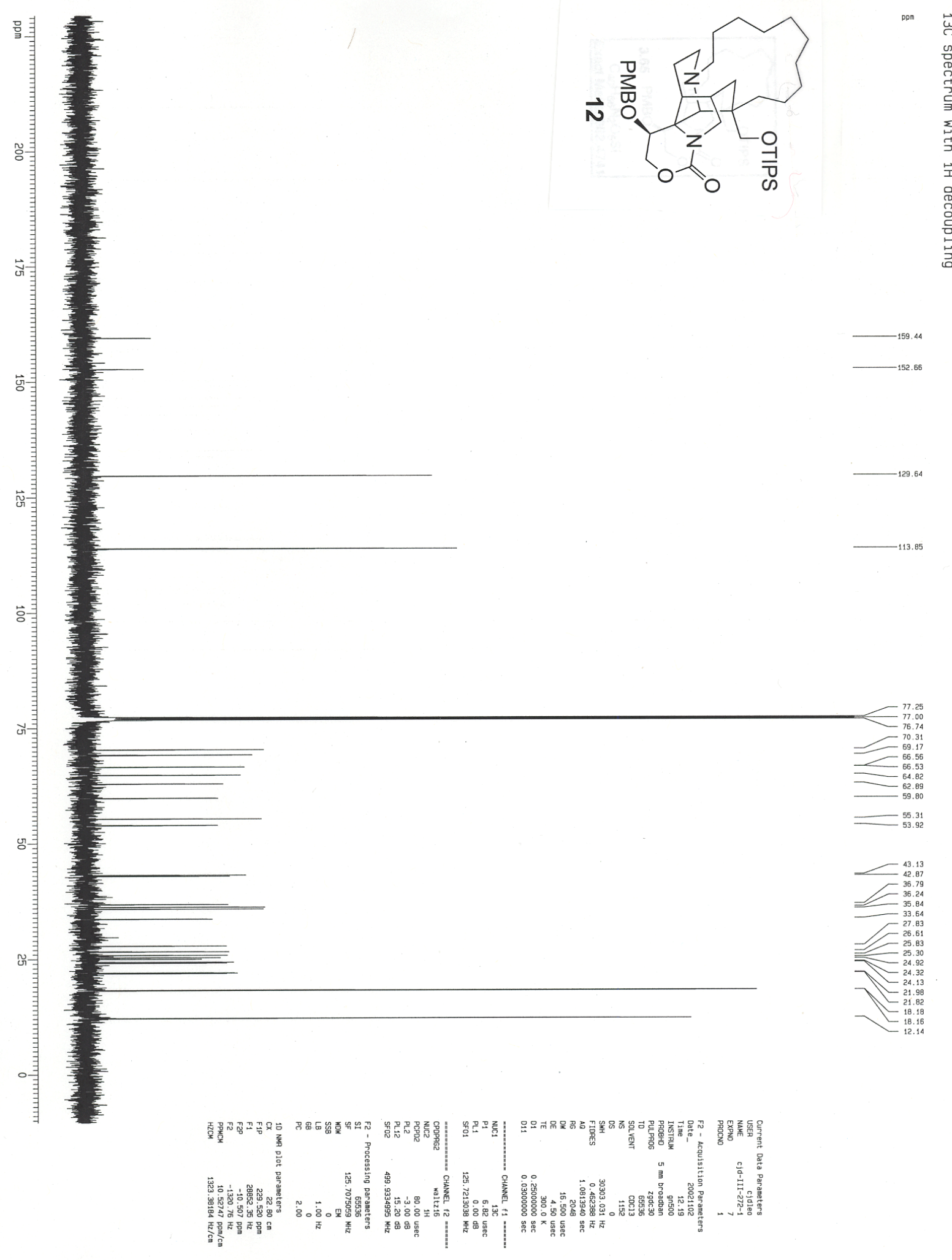



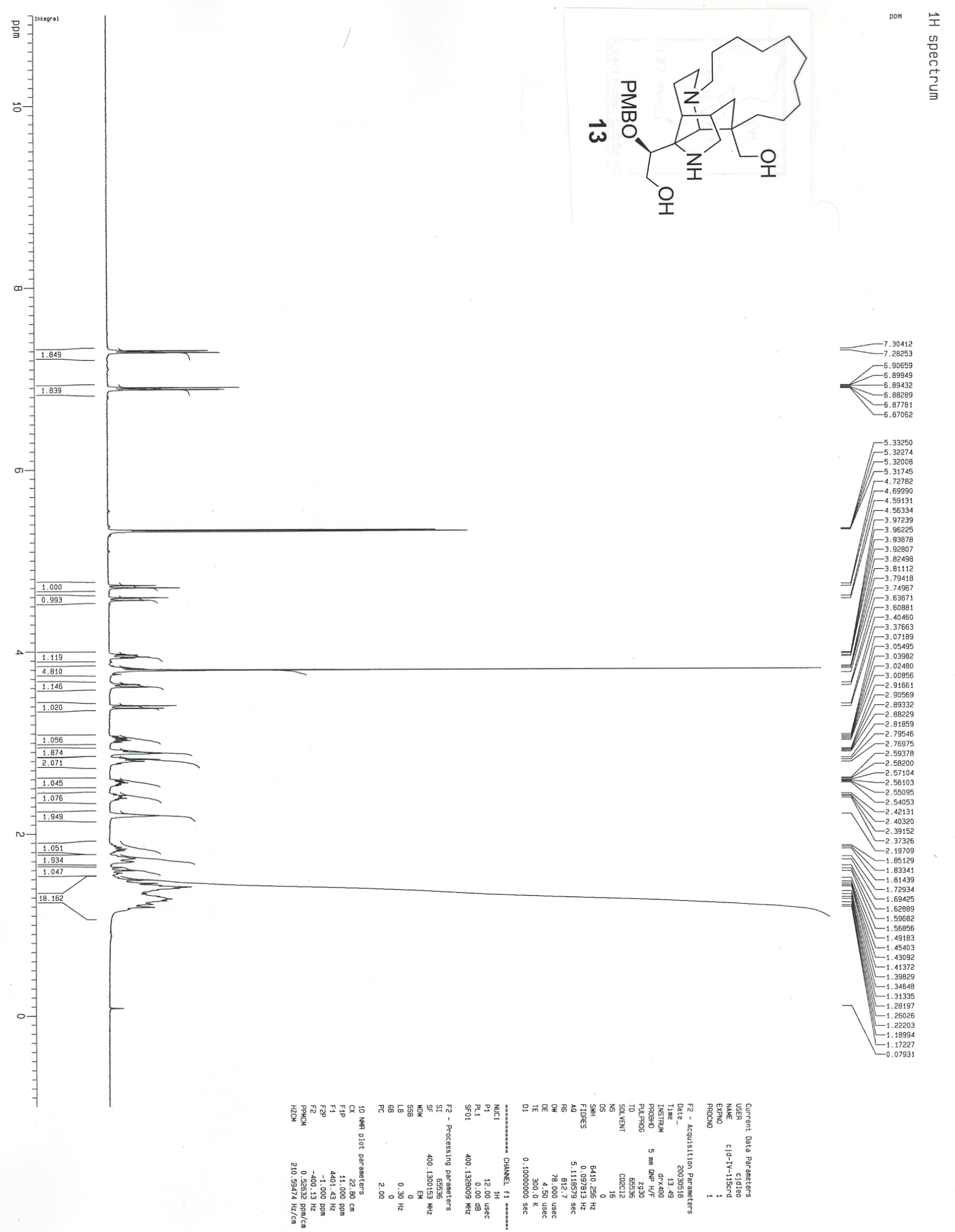


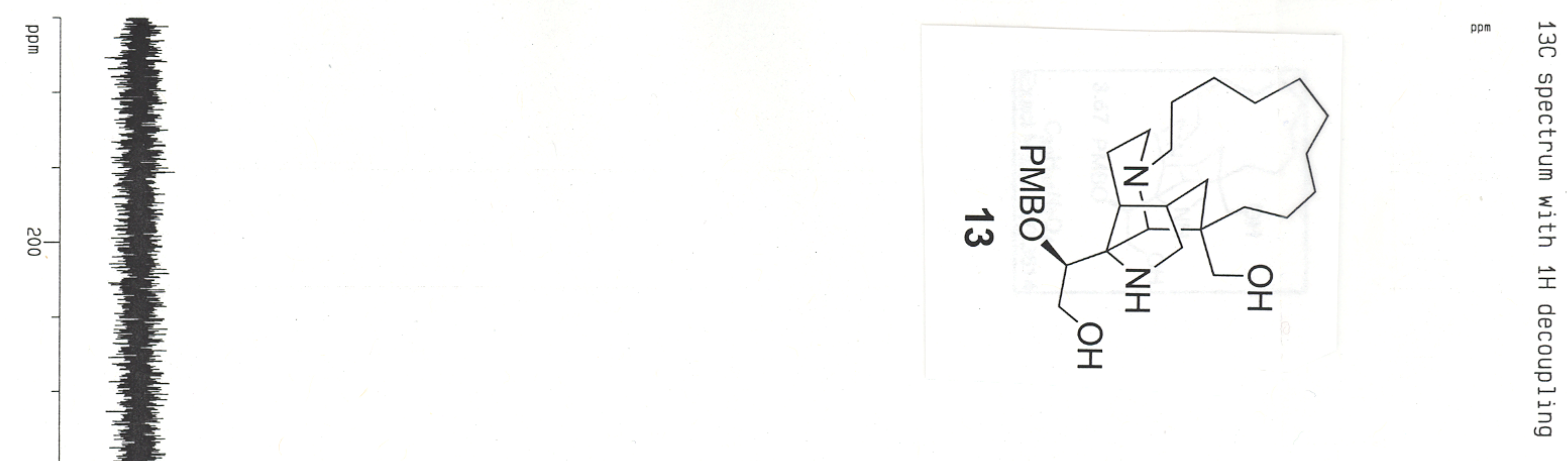




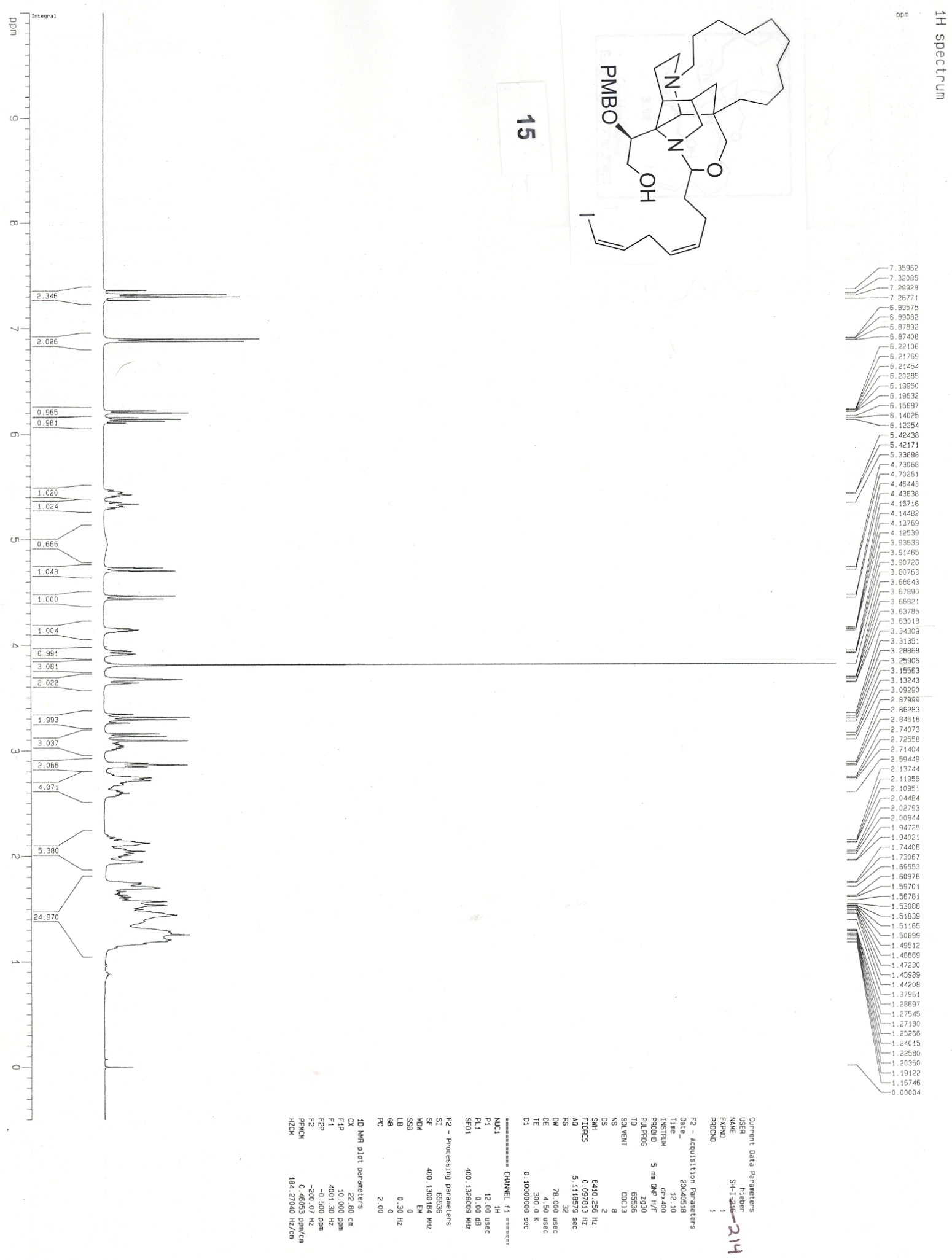




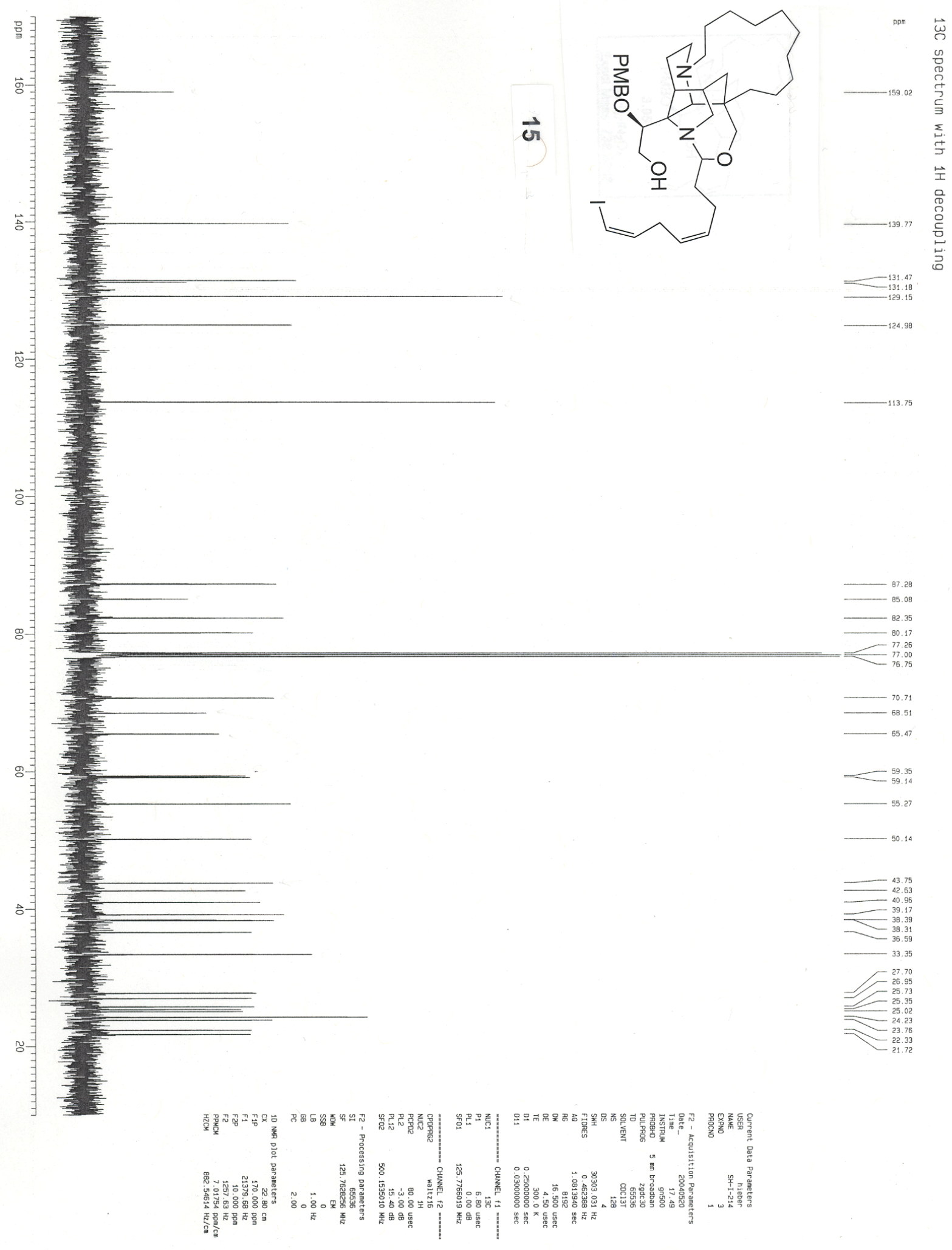



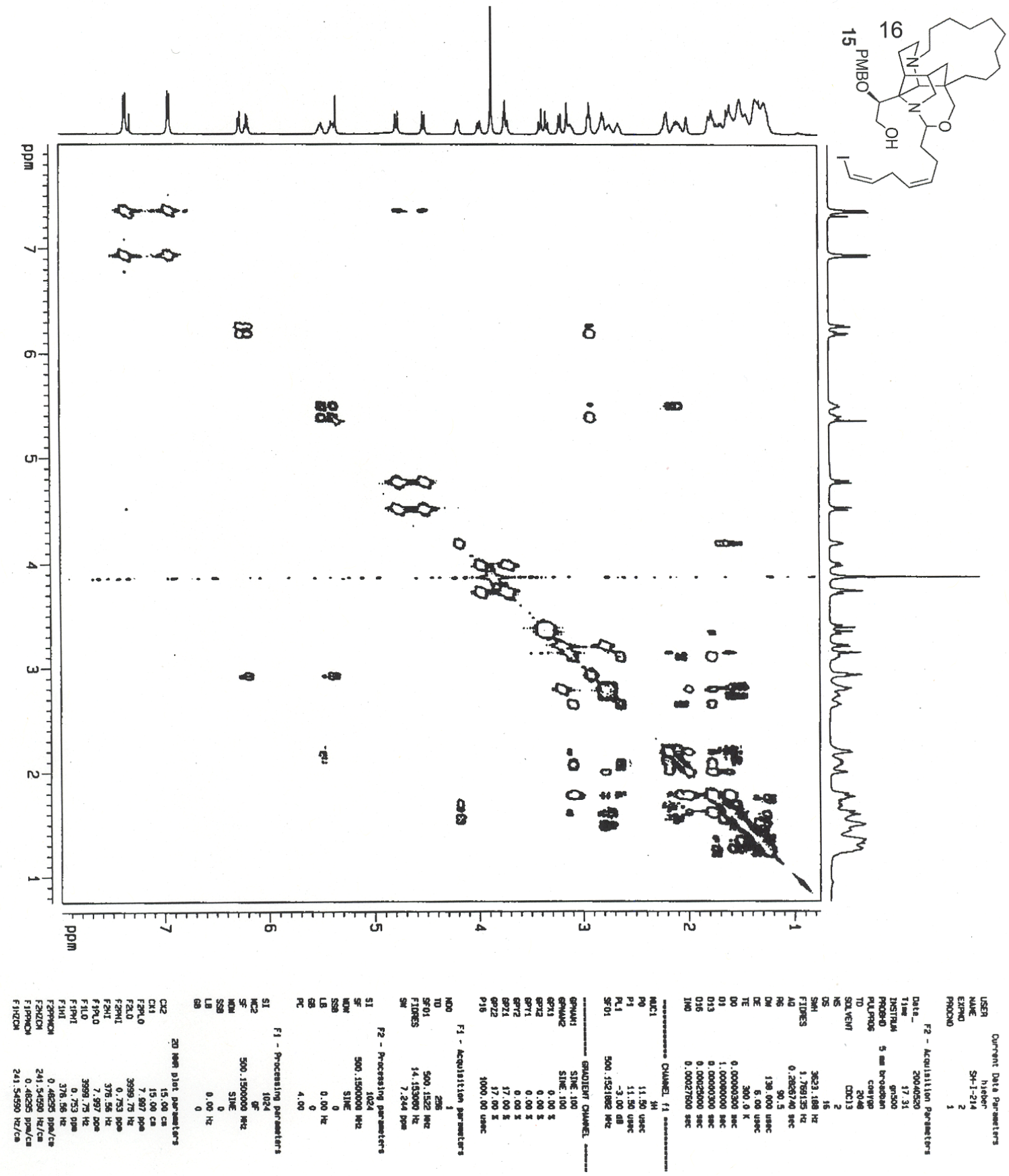


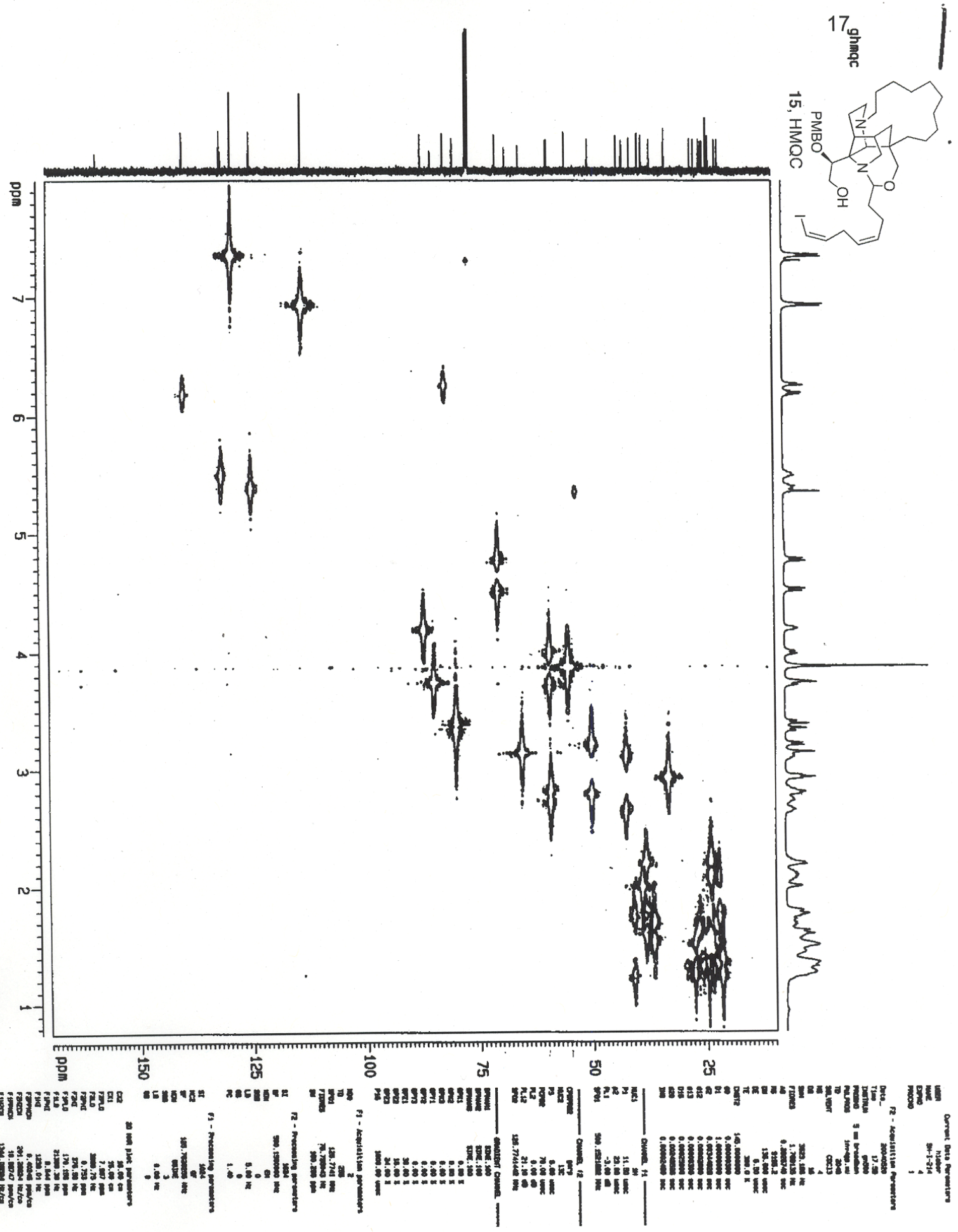




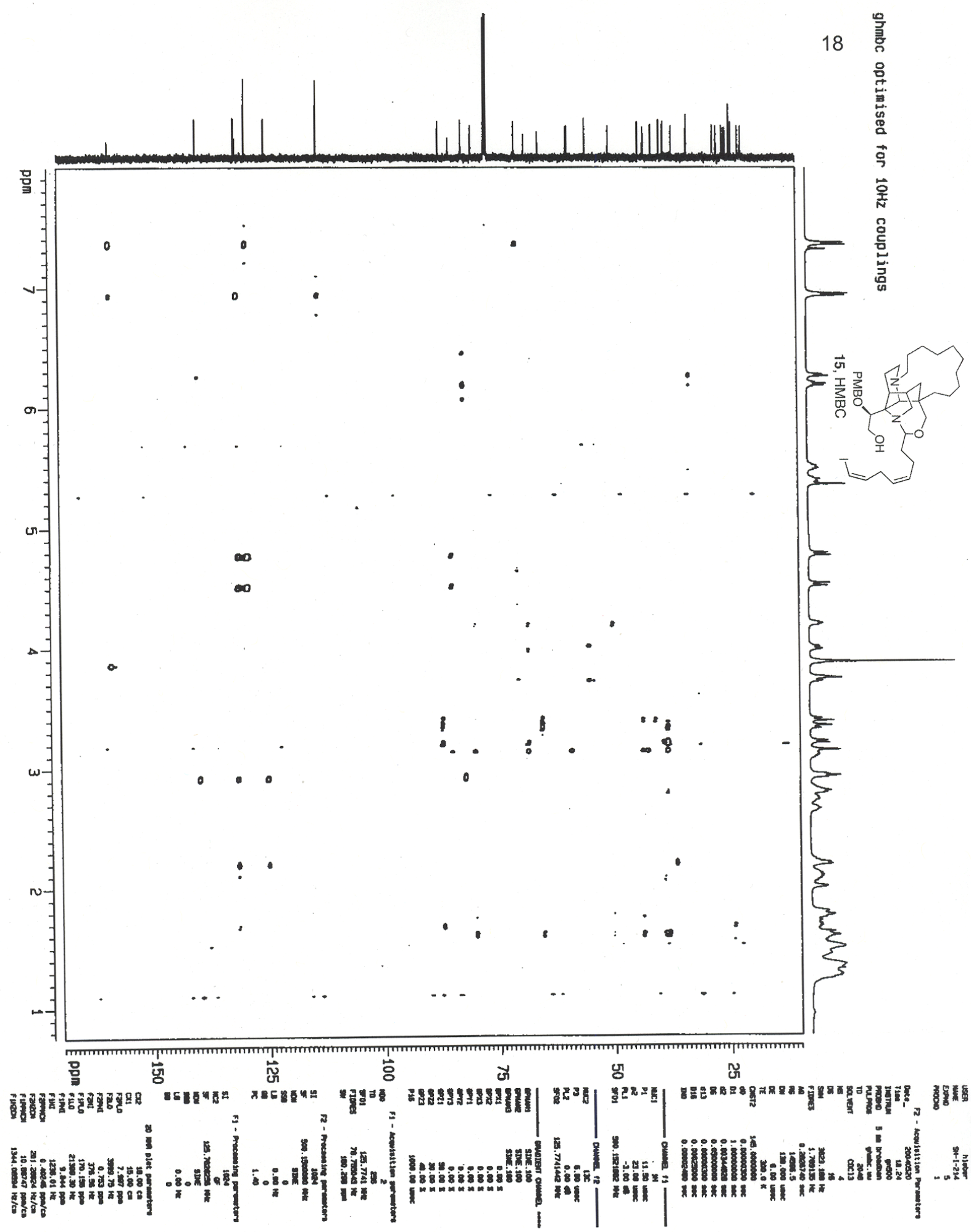




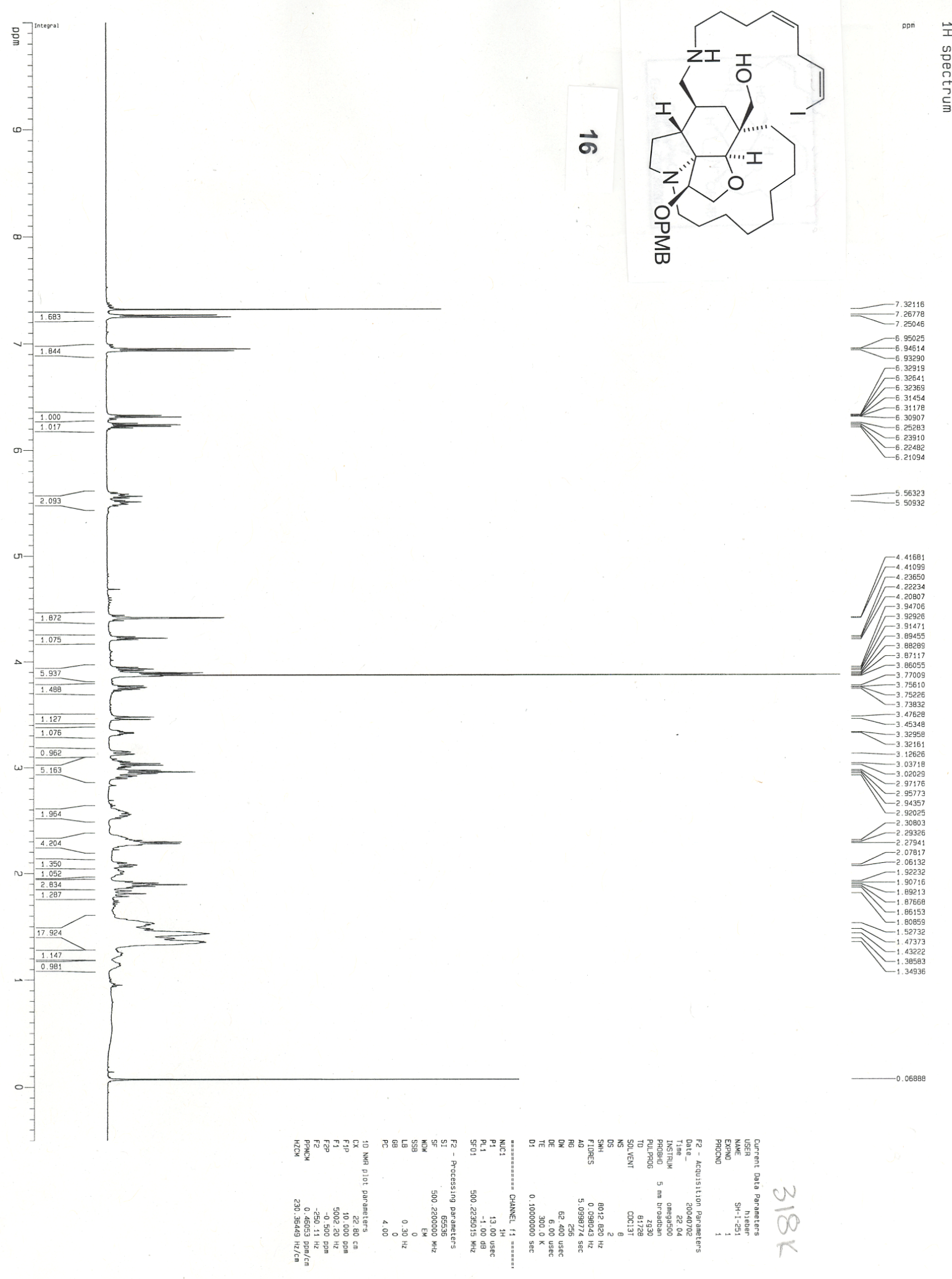


S30

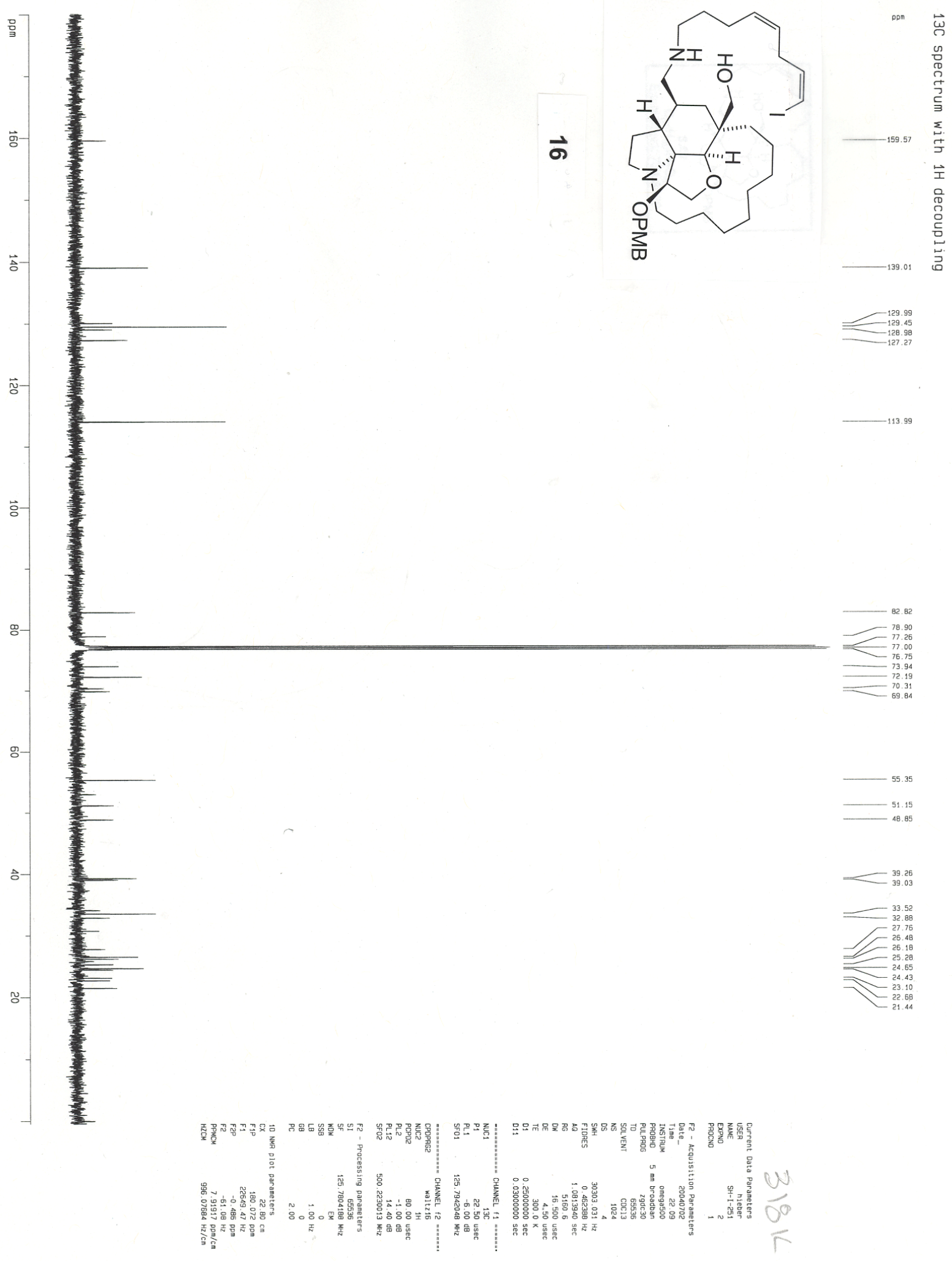



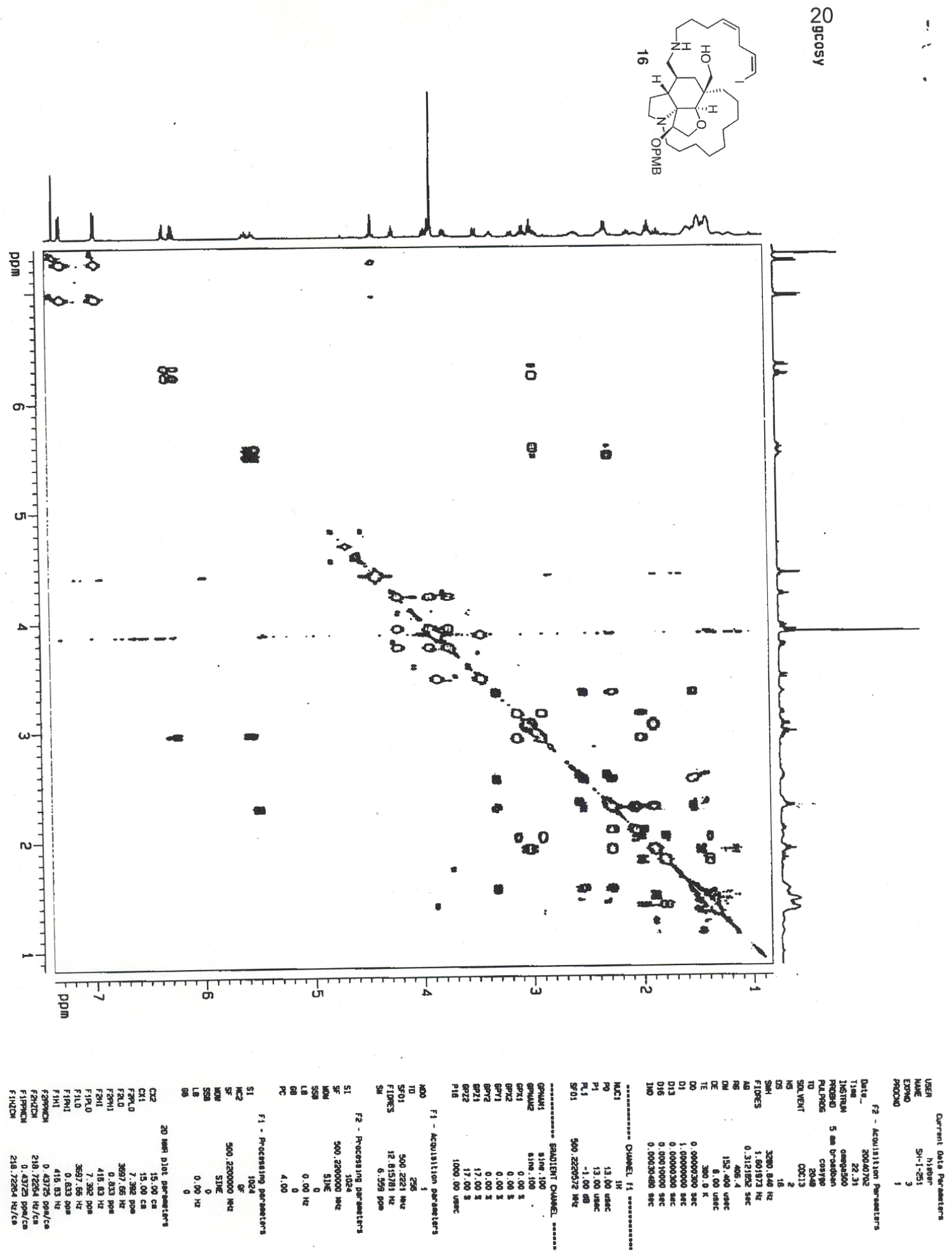

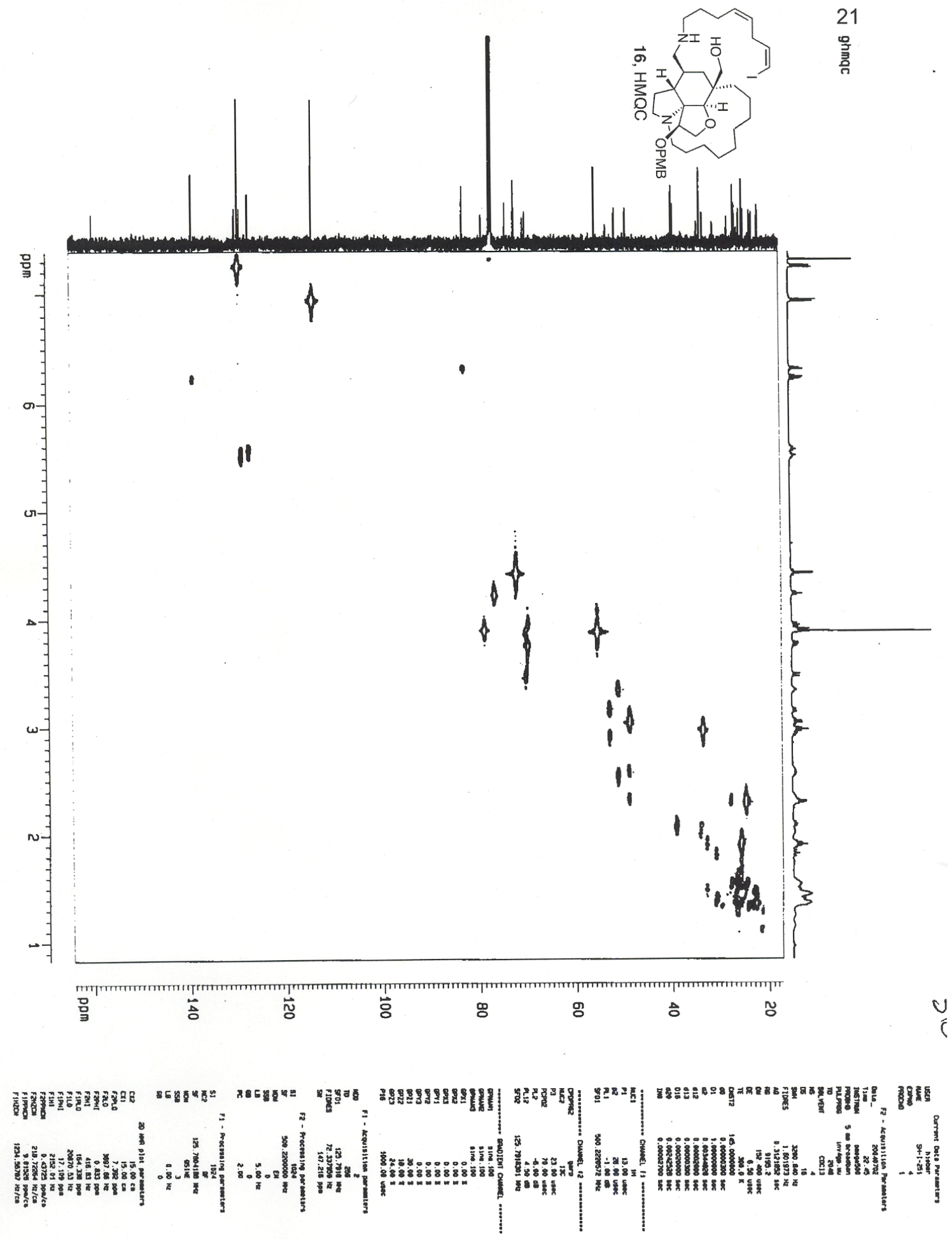

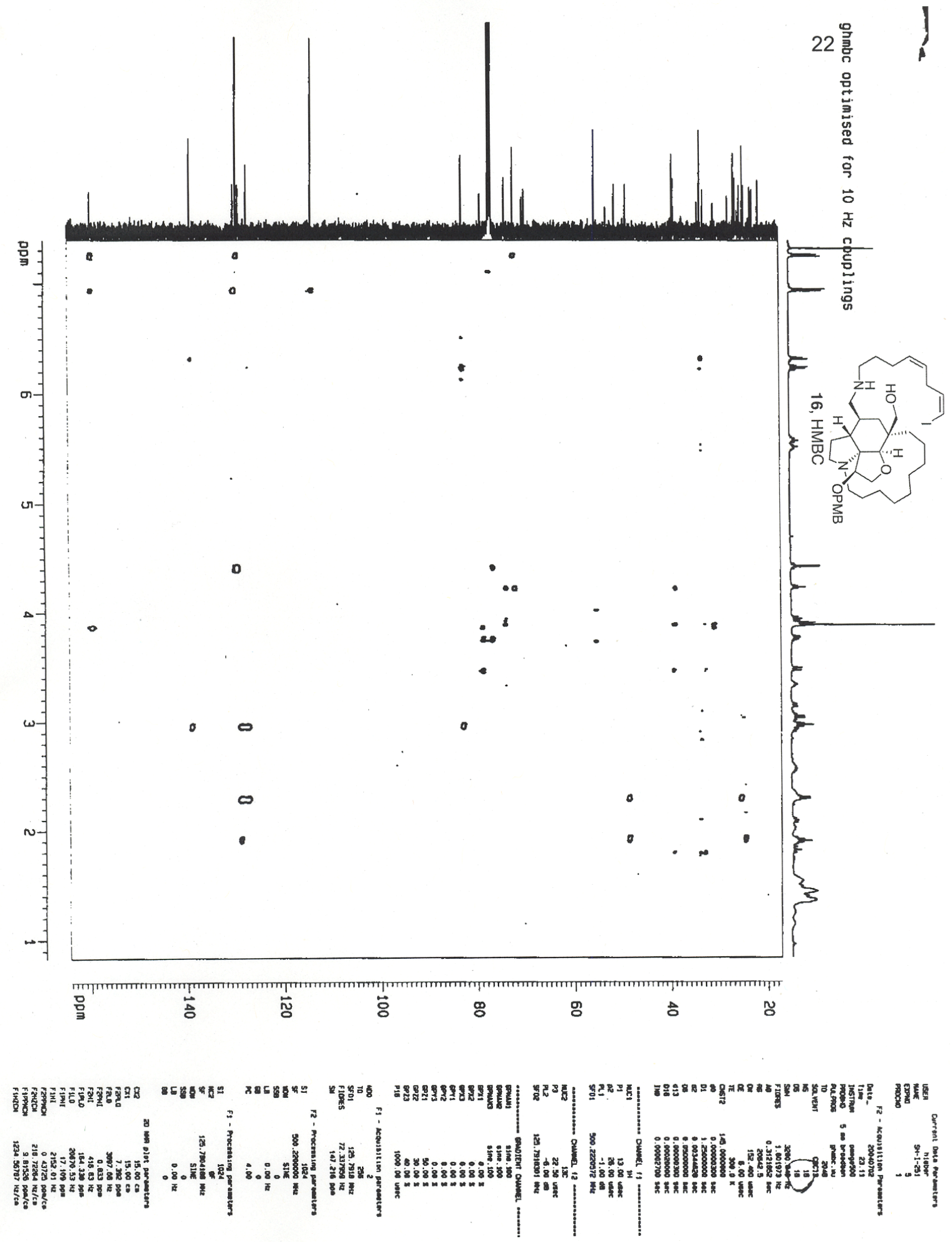

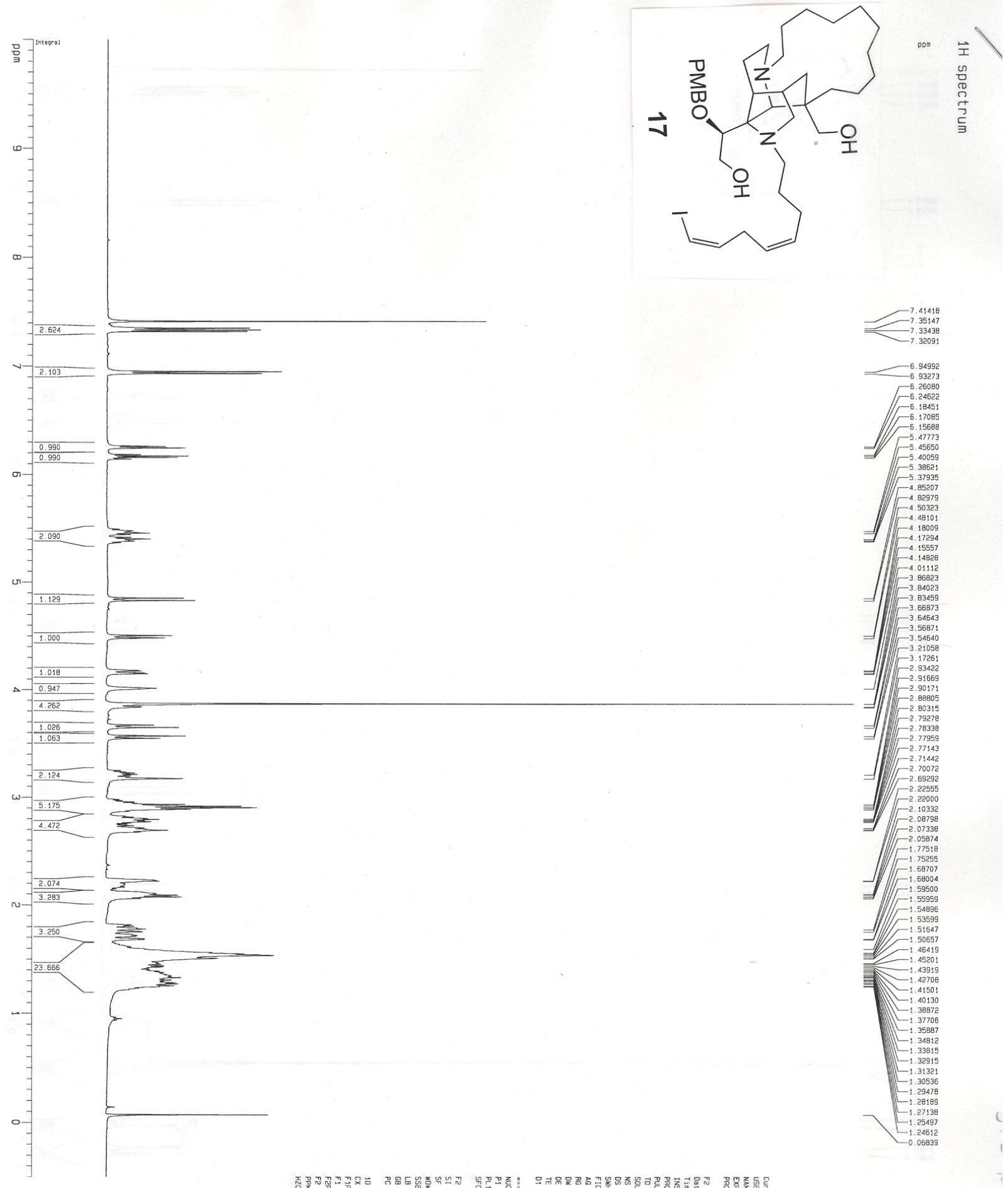
S35
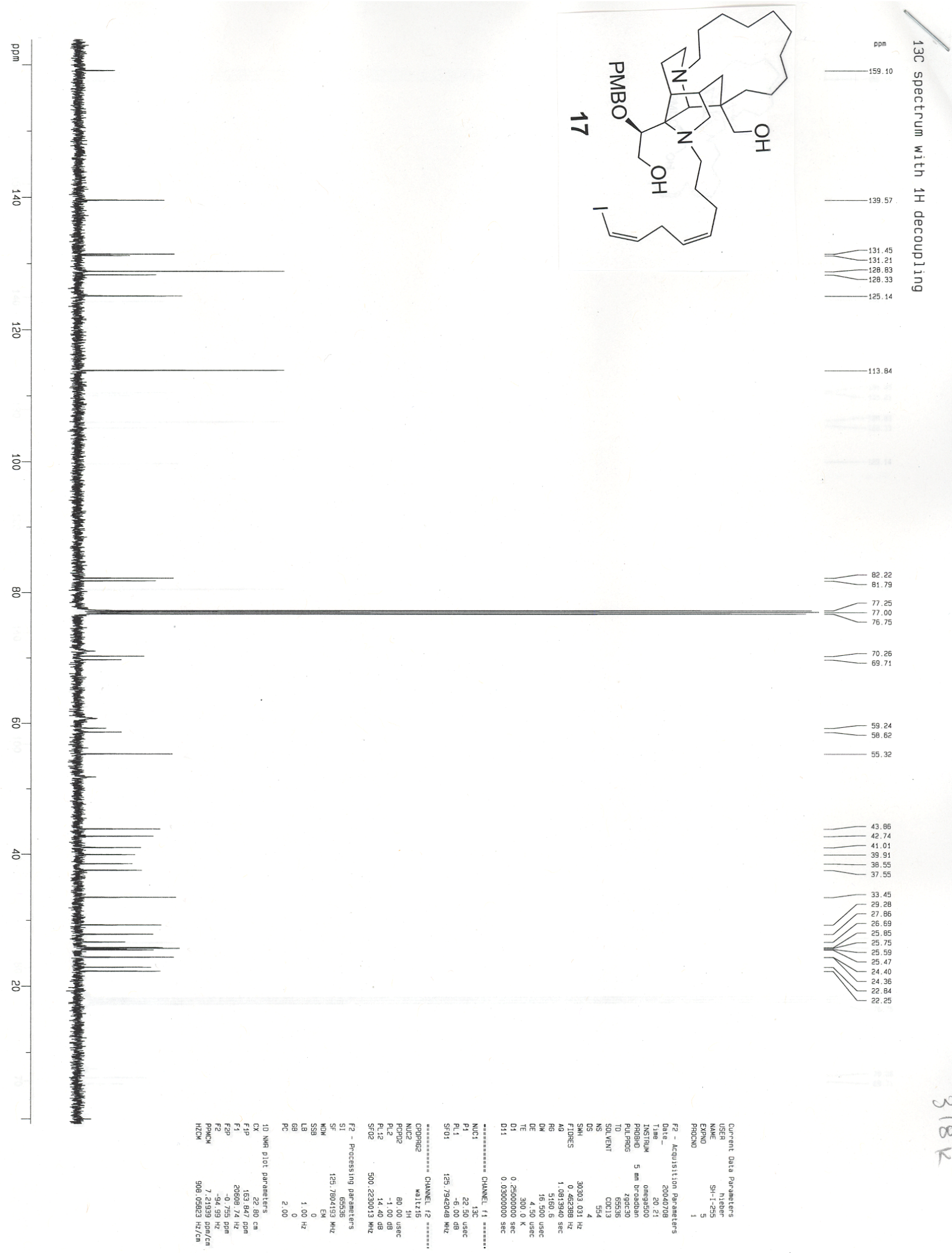

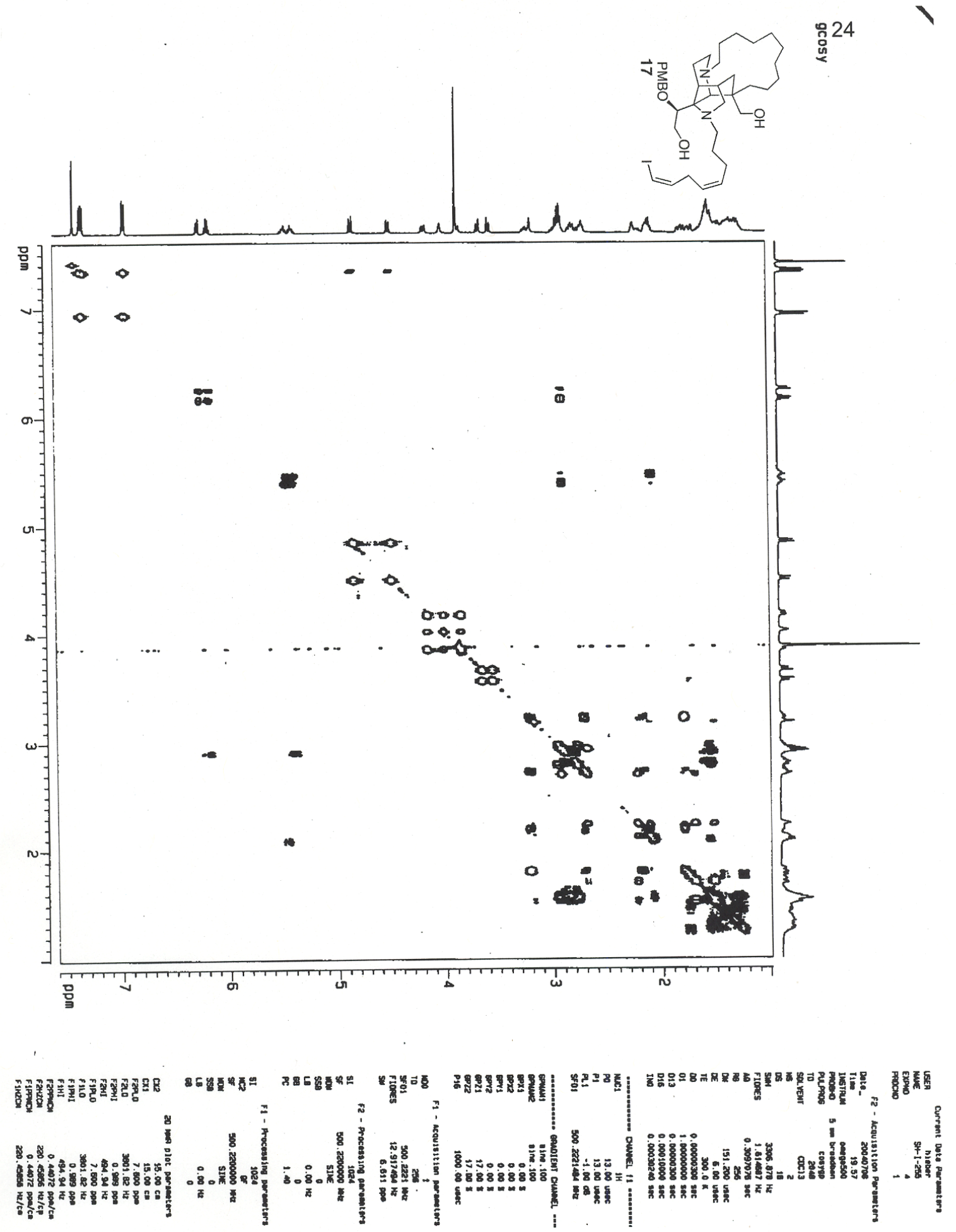

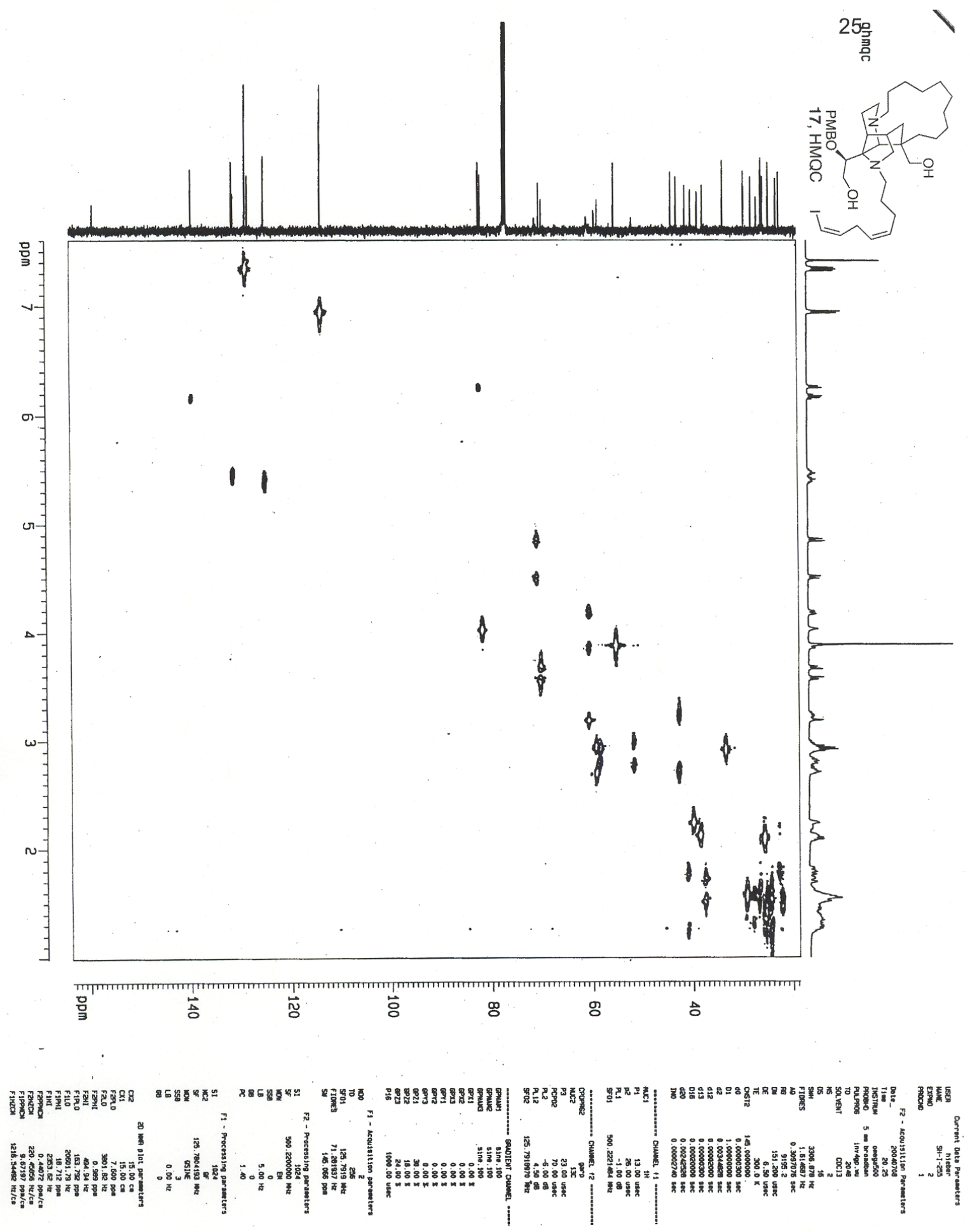

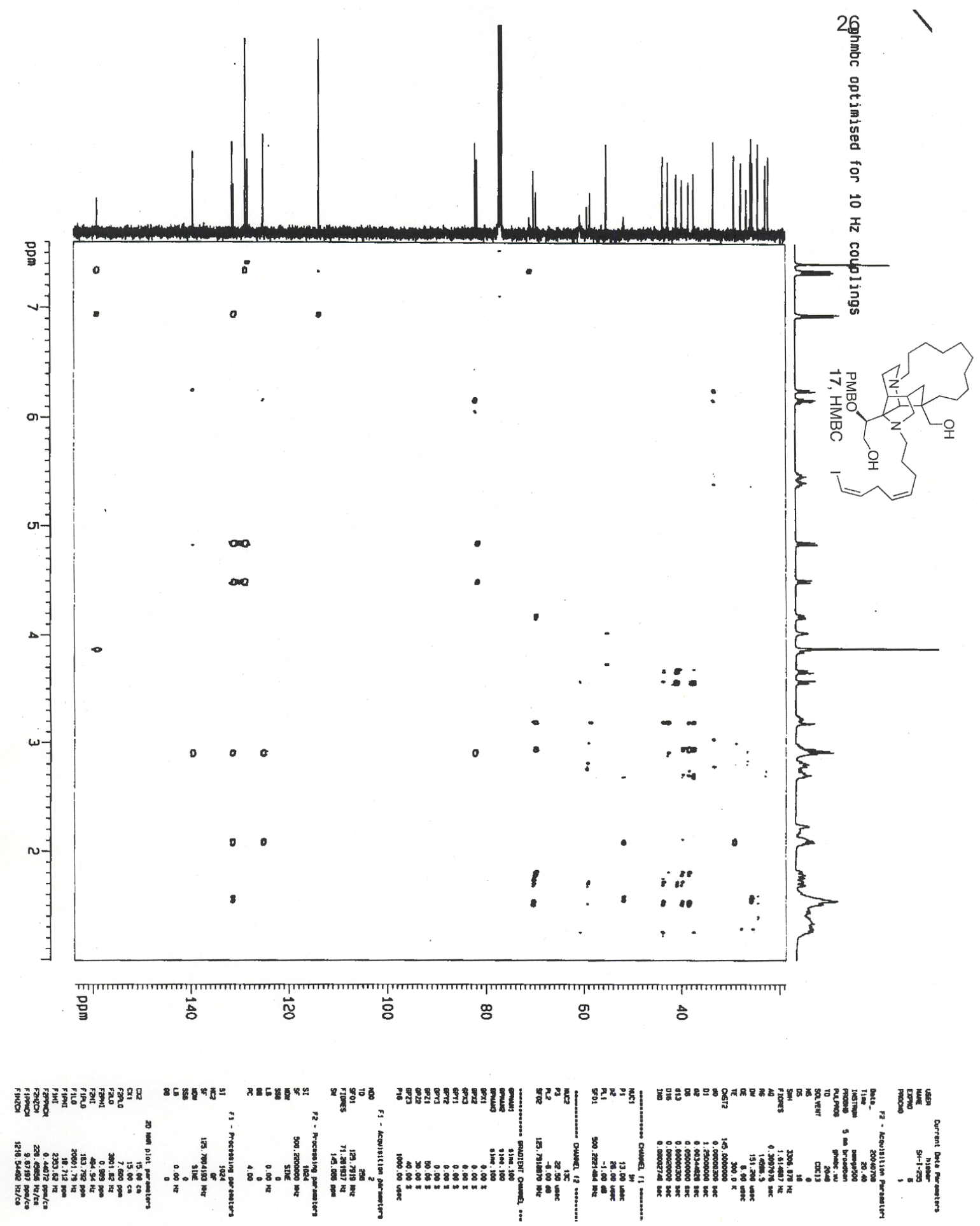